\title{
Condições de trabalho das equipes de saúde bucal no Programa Saúde da Família: o caso do Distrito Sanitário Norte em Natal, RN*
}

\author{
Evelin Cristina Araújo da Rocha** \\ Maria Arlete Duarte de Araújo***
}

SumÁrio: 1. Introdução; 2. A inserção das equipes de saúde bucal no Programa Saúde da Família: breves considerações; 3 . As equipes de saúde bucal no município de Natal, RN; 4. Percurso metodológico; 5 . Um olhar sobre as condições de trabalho das equipes de saúde bucal no Distrito Sanitário Norte em Natal, RN; 6. Conclusão.

Summary: 1 . Introduction; 2 . The integration of oral health teams in the Family Health Program: brief considerations; 3 . The oral health teams in the city of Natal, RN; 4. Methodological path; 5. A look on the working conditions of the oral health teams in the in the North Health District in Natal, RN; 6. Conclusion.

Palavras-chave: equipes de saúde bucal; condições de trabalho; ações de saúde bucal; avaliação.

KEYWORDs: oral health teams; working conditions; oral health actions; assessment.

Este artigo verifica as condições de trabalho dos dentistas nas equipes de saúde bucal (ESBs) inseridas no Programa Saúde da Família (PSF). O universo da pesquisa foi composto por todos os dentistas lotados nas unidades básicas de saúde (UBSs). Foram aplicados questionários para identificar as características operacionais de funcionamento, o ambiente físico, a disponibilidade de equipamentos e insumos, a

\footnotetext{
* Artigo recebido em dez. 2007 e aceito em ago. 2008.

** Mestre em administração pela Universidade Federal do Rio Grande do Norte (PPGA/UFRN). Endereço: Rua Velho Modesto, 1450 - Morro Branco - CEP 59056-390, Natal, RN, Brasil. E-mail: evelincris@bol.com.br.

*** Professora titular do Departamento de Ciências Administrativas da Universidade Federal do Rio Grande do Norte (UFRN), professora do Programa de Pós-Graduação em Administração da UFRN, doutora em administração pela Escola de Administração de Empresas de São Paulo, da Fundação Getulio Vargas (Eaesp/FGV). Endereço: Av. Rodrigues Alves, 410, ap. 1100 - Bairro Petrópolis — CEP 59020-200, Natal, RN, Brasil. E-mail: arletearaujo@natal.digi.com.br.
} 
autonomia, o poder de decisão e a integração com as equipes do PSF. Os resultados apontam que vários aspectos são identificados pelos dentistas como limitação ao trabalho, tais como: local de trabalho com estrutura física inadequada, disponibilidade de equipamento, instrumental e material inadequados à realização das ações previstas, a ausência de articulação da referência e contrarreferência para que as necessidades de maior complexidade sejam atendidas, bem como a baixa capacitação dos profissionais para o trabalho em equipe. Apesar das dificuldades, há uma compreensão de que a inclusão das ações de saúde bucal no PSF do Distrito Sanitário Norte trouxe a incorporação de novos valores às práticas exercidas, abrindo a possibilidade para que haja uma verdadeira substituição das práticas tradicionais exercidas e um novo jeito de se fazer saúde.

Working conditions of oral health teams in the Family Health Program: the case of North Health District in Natal, RN, Brazil

This article verifies the working conditions of oral health teams (OHT) in the Family Health Program (FHP). The target population in the research was composed of all dentists working in basic health units (BHUs). Questionnaires were used to identify the operational characteristics, physical environment, equipment availability, autonomy, power of decision, and integration with FHP teams. The results demonstrate that some aspects identified by the dentists as limitations to their work are: workplace with inadequate physical structure, equipment availability, inadequate instruments and materials for their daily routine, absence of reference and counter-reference articulation so that more complex needs are met, as well as the inability of health professionals to work in teams. Despite difficulties, there is some understanding that the inclusion of oral health actions in the North Health District in Natal incorporated new values to the practice, making it possible to replace traditional practices with a new way of promoting health.

\section{Introdução}

A partir dos anos 1980, num contexto de transição democrática, reforçaram-se as expectativas de formatação de uma nova institucionalidade para as políticas sociais no país, visando ao resgate da dívida social acumulada em décadas de exclusão e a ampliação dos direitos sociais.

Assim, temas como descentralização, transparência dos processos decisórios, ampliação da participação popular, valorização dos direitos sociais e tendência à universalização do acesso aos programas sociais ganham importância e passam a ser identificados como instrumentos de democratização.

O marco legal da reorganização do sistema de saúde no Brasil se dá com a inscrição na Constituição Federal de 1988 dos princípios e diretrizes do Sistema Único de Saúde (SUS), passando a saúde a ser vista por meio de um 
conceito ampliado que norteia a mudança progressiva dos serviços, evoluindo de um modelo assistencial centrado na doença e baseado no atendimento a quem procura para um modelo de atenção integral à saúde, com a incorporação progressiva de ações de promoção e proteção, ao lado das propriamente ditas de recuperação.

Quase uma década após a sua implantação, o SUS havia logrado resultados pouco perceptíveis na estruturação dos serviços de saúde, sobretudo por não promover mudanças significativas no modelo assistencial vigente. Em consequência, a década de 1990 foi marcada pela adoção de estratégias institucionais destinadas a garantir que os programas sociais atingissem os segmentos menos favorecidos da sociedade.

É assim que o Programa Saúde da Família (PSF) surge no Brasil, em 1994, como uma política nacional de saúde, num contexto rico de influências institucionais que determinaram a sua incorporação como política prioritária para o setor de saúde do país.

Constituindo-se um modelo inovador de reestruturação e reorganização da atenção básica à saúde, pautado nos princípios de universalidade, integralidade, equidade, descentralização, hierarquização e participação popular, o processo de implementação do PSF no Brasil foi claramente uma medida de reorganização e consolidação dos princípios do SUS, buscando transformá-los em ação efetiva.

Constituído por equipes multiprofissionais, formadas por médicos, enfermeiros, auxiliares de enfermagem, agentes de saúde e, mais recentemente, por dentistas, cada equipe se responsabiliza pelas famílias de uma determinada área no município; as atividades exercidas caracterizam-se por sua abrangência e por ações intersetoriais como: saúde, educação, saneamento, meio ambiente, entre outras.

A inclusão do dentista nas equipes do Programa Saúde da Família assinala uma reorganização da atenção à saúde bucal no país e estabelece um novo cenário na odontologia brasileira, através de uma nova forma de organizar a atenção básica à saúde, criando condições para consolidar nas ações da prática em saúde bucal, no nível da atenção básica, a validação dos princípios constitucionais do SUS. Com isso, amplia-se a compreensão da saúde bucal do povo brasileiro, que passa a estar inserida num conceito amplo de saúde, integrada às demais práticas de saúde coletiva, como parte integrante da saúde geral do indivíduo, essencial para sua qualidade de vida.

A inserção oficial da odontologia no contexto do Programa Saúde da Família (PSF) se deu pela publicação da Portaria GM/MS no 1.444, de 28 de dezembro de 2000 , que estabelecia incentivo financeiro para a reorganiza- 
ção da atenção à saúde bucal e defendia uma inversão do modelo vigente com o desafio de tornar as ações em saúde bucal um direito de todos os cidadãos brasileiros.

Em 2004, dando continuidade à reorientação no modelo de atenção à saúde bucal do país, o Ministério da Saúde publica documento contendo as Diretrizes da Política Nacional de Saúde Bucal (Ministério da Saúde, 2004).

De acordo com o documento, essa reorientação tem os seguintes pressupostos: assumir o compromisso de qualificação da atenção básica para que haja qualidade e resolubilidade na prestação dos serviços; garantir uma rede de atenção básica articulada com toda a rede de serviços de saúde; assegurar a integralidade nas ações de saúde bucal; utilizar a epidemiologia e as informações sobre o território para subsidiar o planejamento das ações; acompanhar o impacto das ações de saúde bucal por meio de indicadores adequados; centrar a atuação na vigilância à saúde; incorporar a saúde da família como estratégia na reorganização da atenção básica; definir política de educação permanente para os trabalhadores em saúde bucal; estabelecer política de financiamento para o desenvolvimento de ações; e definir uma agenda de pesquisa científica (Ministério da Saúde, 2004).

Com a inclusão do dentista no contexto do PSF, com a criação das equipes de saúde bucal (ESBs), o Ministério da Saúde propõe uma mudança das práticas de intervenção e a priorização de ações de prevenção e promoção. Com isso, a saúde bucal passa a ser compreendida como um direito básico acessível a todos os cidadãos, pautada na universalidade, equidade e integralidade, estruturando-se de forma descentralizada e hierarquizada em diferentes níveis de complexidade, e regulada por meio do controle social.

Em Natal, em função do processo de organização do sistema de saúde, em 1994, é implantado o PSF pela Secretaria Municipal de Saúde (SMS), por meio de convênio firmado com o Ministério da Saúde. Esse processo iniciou-se pelo Distrito Sanitário Oeste, onde inicialmente foram implantadas 19 equipes, seguido pelo Distrito Sanitário Norte, onde foram implantadas 38 equipes. Desde a promulgação da Lei no 3.878 , de 7 de dezembro de 1989, dispondo sobre a organização político-administrativa da Prefeitura de Natal, haviam sido criadas as regiões administrativas Norte, Sul, Leste e Oeste como primeira iniciativa de zoneamento urbano para tratamento microlocalizado dos problemas identificados no contexto de atuação das políticas públicas. Esse processo culminou, em 1990, com a divisão do município em quatro distritos sanitários, respeitando a mesma conformação das regiões administrativas (SMS, 2007).

Compreendendo a magnitude dos problemas associados à saúde bucal, com situação claramente delineada nas unidades epidemiológicas, a SMS com 
a inclusão das equipes de saúde bucal no PSF do Distrito Sanitário Norte, em 2001, optou pela reestruturação de sua rede de serviços, na perspectiva de organizar a atenção, reforçando o caráter integral e inclusivo, ofertando ações de promoção, prevenção e recuperação com ênfase em práticas que tivessem por escopo a garantia do acesso e resolução dos problemas ao cidadão e à sociedade (SMS, 2007).

No entanto, conforme informações repassadas pela Secretaria Municipal de Saúde e pelas coordenadoras do PSF no Distrito Sanitário Norte, após seis anos da inclusão das primeiras ESBs no distrito ainda não há nenhuma avaliação sobre a atuação do programa. Logo, partindo do pressuposto de que uma correta atuação das ESBs possibilita a ampliação do acesso da população brasileira às ações de promoção e recuperação da saúde bucal, bem como de prevenção de doenças e agravos a ela relacionados, este artigo descreve e analisa as condições de trabalho das equipes de saúde bucal (ESBs) do Distrito Sanitário Norte do município de Natal, RN, à luz das diretrizes do Programa Saúde da Família.

$\mathrm{O}$ artigo está estruturado da seguinte forma: em primeiro lugar discute a inserção das equipes de saúde bucal no Programa Saúde da Família; depois discute a atuação das equipes de saúde bucal no município de Natal; em seguida, apresenta a metodologia da pesquisa; analisa os dados relativos às condições de trabalho; e tece considerações sobre a adequação ou não das condições de trabalho das equipes de saúde bucal para a consolidação de um novo jeito de fazer saúde bucal.

\section{A inserção das equipes de saúde bucal no Programa Saúde da Família: breves considerações}

O reconhecimento da crise enfrentada por um modelo assistencial de saúde baseado na doença, que atuava exclusivamente sobre a demanda espontânea, com ênfase na cura, baixa capacidade de resolubilidade, marcado pela centralização do poder e do saber na pessoa do médico, e pela falta de interação com a comunidade, suscitou a necessidade de uma nova estratégia para o setor.

Assim, surge formalmente o Programa Saúde da Família (PSF) como uma política pública de saúde no ano de 1994.

Segundo Andrade, Bezerra e Barreto (2005) a decisão política de se reorganizar a rede de assistência à saúde com uma política que apontasse para a universalização do acesso da população à atenção básica e consolidasse o re- 
cente processo de descentralização, proposto pelo SUS, foi o norte inspirador da implementação do PSF em diversos municípios brasileiros.

O PSF pode ser definido como um modelo de atenção básica, operacionalizado por ações preventivas e promocionais das equipes de saúde da família, comprometidas com a integralidade da assistência à saúde, com foco na unidade familiar, consistente com o contexto socioeconômico, cultural e epidemiológico da comunidade em que está inserido.

Para melhor compreensão da organização e operacionalização do modelo, alguns conceitos são fundamentais na definição do Programa Saúde da Família.

A equipe de saúde da família é composta por um grupo interdisciplinar de profissionais envolvidos na cadeia de assistência integral e primária à saúde - médico generalista, enfermeiro, auxiliar de enfermagem e agentes comunitários de saúde. Recentemente, houve também a inclusão de odontólogos nas equipes com a finalidade da atenção à saúde bucal.

A unidade familiar, segundo Andrade, Bezerra e Barreto (2005), é entendida como a célula biológica e social dentro da qual o comportamento reprodutivo, os padrões de socialização, o desenvolvimento emocional e as relações com a comunidade são determinados. Logo, para o PSF, conceitualizar a unidade familiar é levar em consideração não só a composição demográfica dos membros da família, mas também as variáveis que descrevam a organização, a situação familiar e as características do ambiente onde a família está localizada.

Ainda segundo Andrade, Bezerra e Barreto (2005) a comunidade representa a esfera sociocultural delimitada por contiguidade geográfica e primariamente definida por aspectos semelhantes da organização da vida dos indivíduos e dependência comum dos mesmos equipamentos sociais e governamentais. O processo de identificação e descrição das comunidades onde as equipes do PSF irão atuar é conhecido por territorialização e adscrição de clientela.

A implementação do PSF ocorreu como uma estratégia de consolidação dos princípios do Sistema Único de Saúde (SUS) no Brasil, visto que o ideário do programa assume o foco da reorganização da atenção básica, garantindo a oferta de serviços à população brasileira e o fortalecimento dos princípios da universalidade, integralidade e equidade do SUS.

Seguindo o princípio da descentralização, por sua vertente municipalista, o PSF busca estimular a organização dos sistemas locais de saúde, pautando-se a partir da aproximação dos serviços com sua própria realidade, envol- 
vendo os atores sociais dessa mesma realidade, favorecendo e fortalecendo o controle social e a participação popular.

A reorganização do SUS a partir do PSF tem valorizado também a ampliação dos espaços democráticos nas instituições de saúde, por meio da instalação de conselhos e conferências que possibilitam a participação dos usuários. Assim, o PSF também contempla a democratização dos serviços de saúde, por meio do planejamento de suas ações em conjunto com a comunidade, o que exige uma mudança de postura dos profissionais de saúde, da comunidade e dos gestores.

Esse processo de reorganização vem sendo construído de maneira gradativa, exigindo mudanças no processo de trabalho, na cultura dos atores envolvidos e nas relações estabelecidas entre eles. Assim, cabe dizer que os gestores municipais e estaduais possuem um papel fundamental no processo de implantação e acompanhamento do programa, pois cabe a eles conduzi-lo, proporcionando respaldo para que os profissionais de saúde sintam-se motivados a realizar as mudanças exigidas e necessárias.

O PSF não encontrou, no início de sua implantação, um cenário favorável ao seu fortalecimento. Segundo o Ministério da Saúde (2003) o seu processo de formulação não estava totalmente concluído e as condições necessárias à sua sustentabilidade não haviam sido definidas de modo suficiente no âmbito institucional. Não havia, por exemplo, definições quanto ao seu financiamento. Contudo, pode-se dizer que a partir das discussões e contradições geradas pelo PSF, ocorreram alterações importantes na maneira de alocação de recursos e nas formas de remuneração das ações em saúde que fortaleceram o debate em torno das modalidades de financiamento para o setor, o que se refletiu na formulação da Norma Operacional Básica de saúde em 1996.

É possível concordar com Viana e Dal Poz (1998), que afirmam que os processos de implementação do PSF e da NOB/96 se intercruzam, produzindo efeitos sinérgicos e, por isso, se configuram como instrumentos do processo de reforma do sistema de saúde no Brasil.

Por caracterizar-se como um programa de atenção básica à saúde, o PSF prioriza ações de promoção da saúde, embora não exclua ações assistenciais de outros níveis de complexidade que possam ser resolvidas com o aparato disponível na comunidade. Entretanto, como papel fundamental de uma rede de atenção básica, deve-se compreender a coordenação de todo o espectro assistencial em saúde, uma vez que pela atenção básica, "identificam-se as necessidades de atendimentos mais especializados, coordenam-se as referências para os profissionais adequados e acompanham-se os resultados terapêuticos e a evolução clínica dos pacientes acompanhados" (Hart, Belsey e Tarimo, citados por Andrade, Bezerra e Barreto, 2005:330). 
Pode-se afirmar, então, que a rede de atenção básica que está sendo buscada pelo PSF possibilita um melhor controle no desperdício de recursos de saúde, ao mesmo tempo que promove a estabilidade e a confiança na relação entre o usuário e o sistema de saúde.

É pertinente dizer que o conceito de saúde que permeia todo o processo de implantação e desenvolvimento do PSF influiu de forma decisiva na mudança da organização do processo de trabalho. A equipe de saúde da família assumiu o desafio da atenção continuada, resolutiva, pautada pelos princípios da promoção da saúde, onde a ação intersetorial é considerada essencial para a melhoria dos indicadores de saúde e de qualidade de vida da população acompanhada.

Segundo o Ministério da Saúde (2003), ao PSF foi atribuída a função de desenvolver ações básicas, no primeiro nível de atenção à saúde, propondo-se a uma tarefa maior do que a simples extensão de cobertura e ampliação do acesso. O programa deveria promover a reorganização da prática assistencial com novos critérios de abordagem, provocando reflexos em todos os níveis do sistema. Daí o seu potencial estruturante sobre o modelo, o que justificou a decisão do Ministério da Saúde de considerá-lo como a principal estratégia de qualificação da atenção básica e reformulação do modelo assistencial de saúde no país.

Por sua vez, no contexto de atenção à saúde, a saúde bucal cada dia mais desponta como uma preocupação tanto no enfoque da promoção e prevenção, quanto no enfoque assistencial.

Com a publicação da Portaria GM/MS no 1.444, de 28 de dezembro de 2000, que estabeleceu incentivo financeiro para a reorganização da atenção à saúde bucal, prestada nos municípios brasileiros, por meio do Programa Saúde da Família, as ações de saúde bucal foram definitivamente incluídas na estratégia do PSF. Esse instrumento foi regulamentado pela Portaria GM/MS no 267, de 6 de março de 2001, que aprova as normas e diretrizes de inclusão da saúde bucal na estratégia do PSF, através do Plano de Reorganização das Ações de Saúde Bucal na Atenção Básica (Ministério da Saúde, 2002).

Desde então, de acordo com o Ministério da Saúde (2002), a carga horária de trabalho desses profissionais deverá ser de 40 horas semanais e cada equipe de saúde bucal deverá atender, em média, 6.900 pessoas, considerando a proporção de uma ESB para cada duas equipes de saúde da família (ESF) em funcionamento. Para os municípios com menos de 6.900 habitantes, poderá ser implantada uma equipe de saúde bucal para uma ou duas equipes de saúde da família. 
Para a habilitação e qualificação das ESBs, o Ministério da Saúde (2002) estabelece as seguintes exigências: município com equipes de saúde da família (ESF) implantadas ou em implantação; plano de implantação de equipes de saúde bucal no PSF que considere a proporção de uma ESB para cada duas ESF; submissão do plano de implantação para aprovação do Conselho Municipal de Saúde; envio do plano pela Secretaria Municipal de Saúde para a Comissão Intergestores Bipartite (CIB) do estado para análise e aprovação; aprovação do plano de implantação e seu envio para o Ministério da Saúde (Departamento de Atenção Básica); publicação pelo Ministério da Saúde, no Diário Oficial da União, da qualificação das ESBs vinculadas ao PSF; cadastro pelo município de todos os profissionais da ESB no Sistema de Informação da Atenção Básica (Siab) de acordo com a modalidade de implantação aprovada na CIB.

Com relação à transferência de recursos os municípios que qualificarem as ações de saúde bucal receberão incentivo financeiro anual por equipe implantada, de forma automática e regular, do Fundo Nacional de Saúde (FNS) para os Fundos Municipais de Saúde, em parcelas mensais correspondentes a $1 / 12$.

Segundo o Ministério da Saúde (2002), o valor do incentivo vai depender da modalidade da equipe implantada, a saber:

v modalidade I - um dentista e um atendente de consultório dentário (ACD). Para essa modalidade o valor repassado é de $\mathrm{R} \$ 13 \mathrm{mil}$;

v modalidade II - um dentista, um atendente de consultório dentário (ACD) e um técnico em higiene dental (THD). Para essa modalidade o valor repassado é de R\$ 16 mil.

Um incentivo adicional, no valor de $\mathrm{R} \$ 5$ mil, será transferido ao município em parcela única, independente da modalidade da equipe de saúde bucal implantada, para a aquisição de instrumental e equipamentos odontológicos. Caso já existam equipamentos no local destinado ao atendimento, tal incentivo poderá ser utilizado para complementá-los, ou ainda para a aquisição de outros instrumentais ou equipamentos de uso odontológico que se façam necessários na atenção básica.

Uma vez implantadas, as ESBs devem atuar em proximidade com a realidade, identificando fatores de risco, famílias em situação de risco, priorizando demandas assistenciais e preventivas e levando as ações de saúde bucal diretamente às comunidades, para que se procure, em conformidade com o Ministério da Saúde (2002), os seguintes objetivos: melhorar as condições de 
saúde bucal da população brasileira; orientar as práticas de atenção à saúde bucal por meio da estratégia de organização da atenção básica preconizada pelo PSF; assegurar o acesso progressivo de todas as famílias residentes nas áreas cobertas pelas equipes de saúde da família às ações de promoção, prevenção e assistência em saúde bucal; capacitar, formar e educar permanentemente os profissionais de saúde bucal para o PSF, por meio da articulação entre as instituições de ensino superior e as de serviço do SUS; e avaliar os padrões de qualidade e o impacto das ações de saúde bucal desenvolvidas, de acordo com os princípios do PSF.

Para isso, a Portaria no 267/GM, publicada pelo Ministério da Saúde em 6 de março de 2001, diz que a inclusão das ações de saúde bucal na estratégia de saúde da família deverá expressar os princípios e diretrizes do SUS e apresentar as características operacionais que constam no quadro 1 .

$$
\text { Quadro } 1
$$

Características operacionais das ações de saúde bucal no PSF

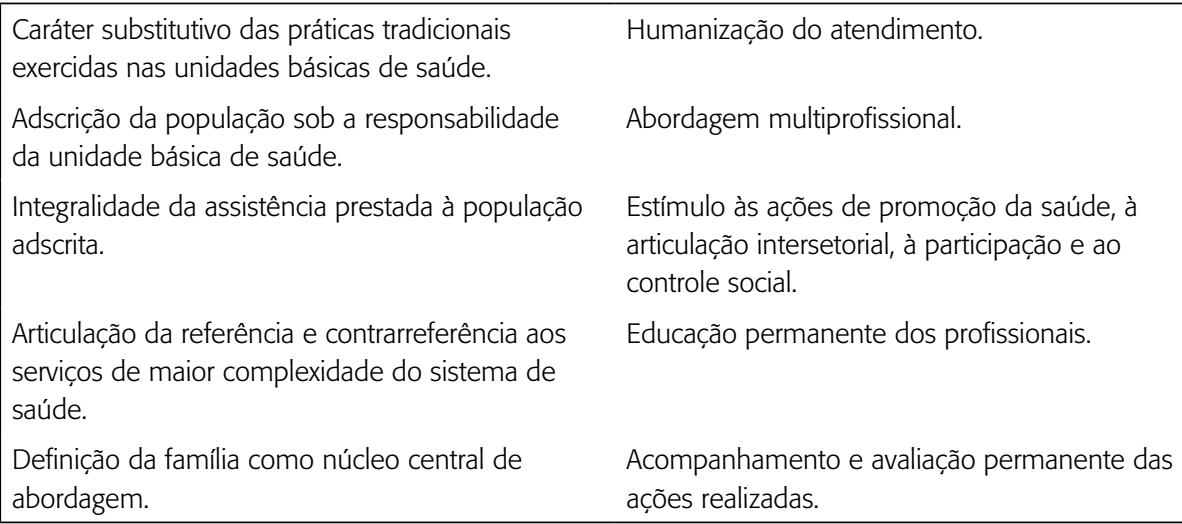

Fonte: Portaria GM/MS no 267, de 6 de março de 2001.

Ainda, nesse sentido, a Portaria GM/MS no 267, de 6 de março de 2001, publicada pelo Ministério da Saúde (2001) estabelece as atribuições comuns aos profissionais de saúde bucal no PSF. Tais atribuições estão no quadro 2.

Ainda nessa perspectiva, visando à operacionalização das ações de saúde bucal na estratégia da saúde da família, o Ministério da Saúde (2001) também determinou atribuições específicas para cada um dos componentes das ESBs. Os quadros 3 e 4 trazem as atribuições profissionais específicas dos cirurgiões-dentistas e do técnico em higiene dental no Programa Saúde da Família. 
Quadro 2

\section{Atribuições dos profissionais de saúde bucal no PSF}

\begin{tabular}{|ll|}
\hline $\begin{array}{l}\text { Participar do processo de planejamento, } \\
\text { acompanhamento e avaliação das ações } \\
\text { desenvolvidas no território de abrangência das } \\
\text { unidades básicas de saúde da família. }\end{array}$ & $\begin{array}{l}\text { Organizar o processo de trabalho de acordo } \\
\text { com as diretrizes do PSF e do plano de saúde } \\
\text { municipal. }\end{array}$ \\
$\begin{array}{l}\text { Identificar as necessidades e as expectativas da } \\
\text { população em relação à saúde bucal. }\end{array}$ & $\begin{array}{l}\text { Sensibilizar as famílias para a importância da } \\
\text { saúde bucal na manutenção da saúde. }\end{array}$ \\
$\begin{array}{l}\text { Estimular e executar medidas de promoção da } \\
\text { saúde, atividades educativas e preventivas em } \\
\text { saúde bucal. }\end{array}$ & $\begin{array}{l}\text { Programar e realizar visitas domiciliares de acordo } \\
\text { com as necessidades identificadas. }\end{array}$ \\
$\begin{array}{l}\text { Executar ações básicas de vigilância } \\
\text { epidemiológica em sua área de abrangência. }\end{array}$ & $\begin{array}{l}\text { Desenvolver açães intersetoriais para a promoção } \\
\text { da saúde bucal. }\end{array}$ \\
\hline
\end{tabular}

Fonte: Portaria GM/MS no 267, de 6 de março de 2001.

Quadro 3

\section{Atribuições profissionais específicas dos cirurgiões-dentistas}

Realizar exame clínico com a finalidade de
conhecer a situação epidemiológica de saúde
bucal da comunidade.

Assegurar a integralidade do tratamento no âmbito da atenção básica para a população adscrita.

Realizar os procedimentos clínicos definidos na NOB/SUS 96 e na Norma Operacional da Assistência à Saúde (Noas).

Prescrever medicamentos e outras orientações em conformidade com os diagnósticos efetuados, emitir laudos, pareceres e atestados.

Executar as ações de assistência integral, aliando a atuação clínica à de saúde coletiva, assistindo as famílias, indivíduos ou grupos específicos, de acordo com plano de prioridades locais.

Coordenar ações coletivas voltadas para a promoção e a prevenção em saúde bucal.

Programar e supervisionar o fornecimento de insumos para as ações coletivas.
Encaminhar e orientar os usuários que apresentarem problemas mais complexos a outros níveis de especialização, assegurando seu retorno e acompanhamento.

Realizar atendimentos de primeiros cuidados nas urgências.

Realizar pequenas cirurgias ambulatoriais.

Supervisionar o trabalho desenvolvido pelo técnico em higiene dental (THD) e pelo atendente de consultório dentário (ACD).

Capacitar as equipes de saúde da família no que se refere às ações educativas e preventivas em saúde bucal.

Registrar no Sistema de Informações Ambulatoriais (SIA/SUS) todos os procedimentos realizados.

Fonte: Portaria GM/MS no 267, de 6 de março de 2001. 
Quadro 4

\section{Atribuições específicas do técnico em higiene dental (THD)}

\begin{abstract}
Realizar, sob a supervisão do cirurgião-dentista, procedimentos preventivos nos usuários para o atendimento clínico.

Realizar procedimentos reversíveis em atividades restauradoras, sob supervisão do cirurgiãodentista.

Auxiliar o cirurgião-dentista (trabalho a quatro mãos).

Realizar procedimentos coletivos na Unidade

Básica de Saúde da Família e em espaços sociais identificados.
\end{abstract}

\section{Cuidar da manutenção e da conservação dos equipamentos odontológicos.}

Acompanhar e apoiar o desenvolvimento dos trabalhos da equipe de saúde da família no tocante à saúde bucal.

Registrar no SIA/SUS todos os procedimentos realizados no âmbito de sua competência.

Fonte: Portaria GM/MS № 267, de 6 de março de 2000.

Por fim, a Portaria GM/MS no 267, diz ainda que é atribuição dos dentistas no âmbito do PSF, realizar os procedimentos clínicos definidos na Norma Operacional Básica do Sistema Único de Saúde - NOB/SUS 96 - e na Norma Operacional da Assistência à Saúde (Noas). O quadro 5 traz os procedimentos clínicos definidos na NOB/SUS 96 e na Noas/2001.

\section{Procedimentos clínicos definidos na NOB/SUS 96 e na Noas}

\begin{tabular}{|ll|}
\hline Consulta odontológica - 1a consulta. & $\begin{array}{l}\text { Curetagem supragengival e polimento dentário } \\
\text { (por hemiarcada). }\end{array}$ \\
$\begin{array}{ll}\text { Aplicação terapêutica intensiva com flúor - por } \\
\text { sessão. }\end{array}$ & $\begin{array}{l}\text { Selamento de cavidade com cimento provisório } \\
\text { (por dente). }\end{array}$ \\
Aplicação de cariostático (por dente). & $\begin{array}{l}\text { Capeamento pulpar direto em dente permanente. } \\
\text { Aplicação de selante (por dente). }\end{array}$ \\
$\begin{array}{l}\text { Pulpotomia em dente decíduo ou permanente e } \\
\text { selamento provisório. }\end{array}$ \\
Controle de placa bacteriana. & Restauração a pino. \\
Escariação (por dente). & Restauração com amálgama de duas ou mais \\
Raspagem, alisamento e polimento - RAP & Restauração com amálgama de uma face. \\
(por hemiarcada). & Restauração com ionômero de vidro de uma face. \\
Restauração com compósito de duas ou mais \\
faces.
\end{tabular}




\begin{tabular}{|ll|}
\hline Restauração com compósito de uma face. & $\begin{array}{l}\text { Restauração com ionômero de vidro de duas ou } \\
\text { mais faces. }\end{array}$ \\
$\begin{array}{ll}\text { Restauração com compósito envolvendo ângulo } \\
\text { incisal. }\end{array}$ & $\begin{array}{l}\text { Exodontia de dente decíduo e de dente } \\
\text { permanente. }\end{array}$ \\
Restauração com silicato de duas ou mais faces. & Remoção de resto radicular. \\
Restauração com silicato de uma face. & Tratamento de alveolite. \\
Restauração fotopolimerizável de duas ou mais & Tratamento de hemorragia ou pequenos \\
faces. & procedimentos de urgência. \\
Restauração fotopolimerizável de uma face. & Ulotomia. \\
Ulectomia. & Necropulpectomia em dente decíduo ou \\
& permanente. \\
Glossorrafia. &
\end{tabular}

Fonte: Norma Operacional Básica do Sistema Único de Saúde (NOB/SUS 96) e Norma Operacional da Assistência à Saúde (Noas/2001).

Desse modo, pelas diretrizes lançadas pela Portaria no 267/GM, o Ministério da Saúde procura orientar a inclusão das ações de saúde bucal no contexto do PSF em todo o território nacional.

\section{As equipes de saúde bucal no município de Natal, RN}

A promulgação da Lei no 3.878 , de 7 de dezembro de 1989, que dispunha sobre a reorganização político-administrativa da Prefeitura de Natal, criando as regiões administrativas Norte, Sul, Leste e Oeste, é a primeira iniciativa de zoneamento urbano para tratamento microlocalizado dos problemas identificados no contexto da atuação das políticas públicas. O resultado das discussões do processo de territorialização, em 1990, culminou com a divisão do município em quatro distritos sanitários, respeitando a mesma conformação das regiões administrativas, que atuavam sob regime de organização em subprefeituras (SMS, 2007).

Em 1994, pelo avanço significativo do processo de organização de seu sistema de saúde, o município de Natal, por meio da Norma Operacional Básica (NOB - SUS 01/93 - MS), habilita-se na condição de gestão semiplena do SUS e assim, no mesmo ano, através de um convênio firmado com o Ministério da Saúde, o Programa Saúde da Família é implantado no município de Natal como uma estratégia de transformação do modelo assistencial vigente. Esse processo foi iniciado pelo Distrito Sanitário Oeste, onde inicialmente fo- 
ram implantadas 19 equipes, seguido pelo Distrito Sanitário Norte com implantação de 38 equipes.

No entanto, por causa das dificuldades encontradas no início do processo, o PSF tornou-se, em Natal, uma estratégia focalizada de expansão dos cuidados básicos de saúde voltada para grupos de maior risco social e, somente em 1997, ocorreu uma implantação mais efetiva do programa, com a definição de prioridades para a prestação de serviços a partir da pessoa, de sua família e de seu entorno comunitário, tendo como eixo estruturante da atenção básica à saúde, a estratégia da saúde da família.

A partir dessa compreensão, desde 2003, a Secretaria Municipal de Saúde de Natal vem intensificando esforços no ajuste organizacional para o aprimoramento da qualidade das ações, serviços e práticas de saúde em todos os níveis de atenção. O propósito é consolidar a estratégia do Programa Saúde da Família como estruturante da atenção básica e, consequentemente, de todo o sistema de saúde, não restringindo esse nível de atenção à oferta de elenco de procedimentos, mas a um conjunto de ações que contemple a integralidade da atenção, resultando na qualidade de vida e propiciando melhora nas condições de saúde da comunidade (SMS, 2006).

Ainda de acordo com a SMS (2007), em 2005, fruto de novas discussões, a região Norte da cidade passa por mais uma delimitação, dessa vez criando para o Sistema Municipal de Saúde, os distritos sanitários Norte 1 e Norte 2, resultante das peculiaridades sociodemográficas e sanitário-epidemiológicas locais e da necessária intervenção do poder público sob uma ótica de gestão participativa com racionalização estratégica de condutas. Essa nova configuração regional no âmbito do município se encontra fortalecida nos atos normativos da administração, com ênfase para a Lei Complementar no 061 de 2 de junho de 2005, Decreto oㅜ 7.642 de 10 de junho de 2005, entre outros instrumentos que norteiam a condução da política municipal.

Hoje o município de Natal conta com 107 equipes do Programa Saúde da Família, implantadas com uma cobertura de $48 \%$ da população nas áreas socioeconomicamente mais vulneráveis, e nos distritos sanitários Norte e Oeste, o programa já atingiu o patamar de $70 \%$ de cobertura. Reitera-se no Plano Municipal de Saúde 2006-2009, publicado pela SMS em 2006, o compromisso com a continuidade da expansão dessa estratégia que melhor traduz a organização da atenção básica (SMS, 2006).

Nesse contexto, compreendendo a magnitude dos problemas associados à saúde bucal, com situação claramente delineada nas unidades epidemiológicas, a SMS com a inclusão das equipes de saúde bucal no PSF, no ano de 2001, optou pela reestruturação de sua rede de serviços, na perspectiva de 
organizar a atenção, reforçando o caráter integral e inclusivo, ofertando ações de promoção, prevenção e recuperação com ênfase em práticas que tenham por escopo a garantia do acesso e resolubilidade ao cidadão e à sociedade (SMS, 2007).

Com isso, o atendimento odontológico passou a ter como principal foco a unidade básica de saúde, uma vez que esse serviço é a porta de entrada do sistema, bem como responsabiliza-se pelo acompanhamento às demandas da população, ordenando o fluxo desde procedimentos simplificados até os de maior complexidade tecnológica.

A rede se estrutura a partir da atenção básica, com os centros de saúde e unidades de saúde da família. Os serviços especializados são compostos pelos centros de especialidades odontológicas (CEO), localizados nos distritos Norte, Leste e Oeste e pelas unidades de pronto-atendimento de urgência odontológica. Está prevista ainda a implantação de um CEO no distrito Sul, totalizando uma unidade de referência por distrito sanitário (SMS, 2007).

Com isso, privilegia-se o atendimento programado tanto para a atenção básica quanto para a especializada, com atendimentos clínicos e procedimentos coletivos, assim como prima-se pela agilidade e eficácia no acolhimento às situações de urgência. Convém ressaltar que esse recorte assistencial ampara-se pelo planejamento de intervenções com especial atenção à clientela com maior vulnerabilidade, fundamentados em critérios epidemiológicos e na estruturação de serviços que pressuponham a vigilância à saúde.

\section{Percurso metodológico}

A pesquisa usada neste artigo é exploratória e descritiva, pois tem como objetivo descrever e analisar as condições de trabalho dos dentistas nas equipes de saúde bucal (ESBs) do Programa Saúde da Família (PSF), no Distrito Sanitário Norte em Natal, RN, para compreender como vem sendo construída a inclusão das ESBs nessa nova proposta de atenção à saúde.

O Distrito Sanitário Norte está localizado na Zona Norte do Município de Natal/RN e subdivide-se em Distrito Sanitário Norte 1 e Distrito Sanitário Norte 2. O Distrito Sanitário Norte 1 é composto por três bairros: Lagoa Azul, Pajuçara e Redinha. O Distrito Sanitário Norte 2 é formado por quatro bairros: Nossa Senhora da Apresentação, Potengi, Igapó e Salinas. As equipes de saúde da família do Distrito Sanitário Norte estão distribuídas em unidades básicas de saúde (UBSs) localizadas nesses bairros com 20 UBSs ao todo. 
As equipes de saúde da família do Distrito Sanitário Norte estão distribuídas em unidades básicas de saúde (UBSs) localizadas nesses bairros com 20 UBSs ao todo. Segundo a SMS (2006) por meio dessas UBSs a cobertura populacional do PSF é de 70\% no Distrito Sanitário Norte.

A pesquisa foi realizada com todos os 58 dentistas lotados nas unidades básicas de saúde do Distrito Sanitário Norte de Natal/RN, caracterizando-se como uma pesquisa censitária. Optou-se por realizar a pesquisa apenas com os dentistas do Distrito Sanitário Norte por considerarmos que os membros da equipe de saúde bucal (ESB) disporiam de maior volume de informações necessárias à compreensão do problema de pesquisa.

$\mathrm{O}$ instrumento escolhido foi o questionário com perguntas fechadas e abertas com o objetivo de identificar as características operacionais de funcionamento de cada UBS, as condições de trabalho dos dentistas, bem como as ações necessárias para que as ESBs do Distrito Sanitário Norte cumpram os objetivos previstos pelo PSF. A coleta dos dados se deu no período de 15 de março a 10 de maio de 2007.

Além das questões específicas sobre condições de trabalho, procurouse também identificar o perfil dos dentistas responsáveis pela saúde bucal no Programa Saúde da Família.

\section{Um olhar sobre as condições de trabalho das equipes de saúde bucal no Distrito Sanitário Norte em Natal, RN}

\section{Perfil dos dentistas}

Os dados revelaram que a faixa etária predominante dos dentistas é de 41 a 60 anos de idade, fato que se explica em razão de esses profissionais terem sido reaproveitados da rede municipal de saúde da qual já faziam parte.

Em relação ao sexo, 60,34\% dos dentistas são mulheres, corroborando com um estudo elaborado pelo Inbrape, realizado em 2003, no qual 57,5\% dos dentistas no Brasil eram do sexo feminino.

Quanto ao tempo de trabalho, constata-se que $41,38 \%$ dos dentistas trabalham no PSF há dois ou três anos. É possível afirmar que o pequeno tempo de permanência nas equipes pode se constituir em fator limitante para o trabalho, dificultando desde a qualificação dos profissionais até o desempenho das ações, tendo em vista a necessidade de adesão e incorporação de novos valores e o exercício de novas práticas de saúde. 
Em relação à renda familiar dos dentistas, varia entre mais de $R \$ 2,5$ mil e mais de $\mathrm{R} \$ 5$ mil, acima do valor da renda média das famílias da zona urbana do estado do Rio Grande do Norte, de R $\$ 1,344$ mil conforme dados da Pesquisa Nacional por Amostra de Domicílios (Pnad) divulgada em setembro de 2006 pelo IBGE.

Os dados de carga horária revelam que todos os dentistas trabalham 40 horas semanais como previsto pelo Ministério da Saúde. Para o MS (2004), a carga horária de 40 horas semanais para os profissionais das equipes de saúde sustenta-se na ideia de que essa é uma condição necessária para a criação de vínculos entre os membros da equipe e entre eles e a população.

No que se refere ao tempo de formação, $46,55 \%$ dos dentistas têm entre 20 e 25 anos de formados. Esse dado também se explica pelo fato de os dentistas terem sido reaproveitados da rede municipal da saúde e permite entender algumas das dificuldades enfrentadas no momento de sua inclusão no PSF, em razão da sua formação profissional ter sido voltada para as questões biológicas e ações curativas.

Isso também é percebido quando a questão se refere à formação, pois $43,10 \%$ não possuem nenhum tipo de especialização, verificando-se, entre a maior parte dos seus portadores, a falta de relação entre o referido curso e a saúde pública ou coletiva. Tal dado expressa um dos principais problemas que surgiu após a implantação do novo modelo de assistência à saúde proposto pelo PSF, que é a falta de formação e capacitação profissional adequada.

\section{Condições de trabalho das equipes de saúde bucal}

Em relação às características operacionais presentes nas ações de saúde bucal desenvolvidas nas UBSs, a tabela 1 revela que 100\% das respostas indicam a humanização do atendimento como a característica operacional mais presente nas ações de saúde bucal realizadas no PSF do Distrito Sanitário Norte. Em seguida, as respostas mais apontadas: família como núcleo central da abordagem, 93,10\%; adscrição da população e substituição das práticas tradicionais anteriormente exercidas nas UBSs, 91,38\%. Por outro lado, apenas $67,24 \%$ das respostas indicam o acompanhamento e avaliação das ações realizadas; $46,55 \%$ a educação permanente dos profissionais; e somente $43,10 \%$ a articulação da referência e contrarreferência aos serviços de maior complexidade. 
Tabela 1

Características operacionais presentes nas ações de saúde bucal realizadas pelos dentistas nas UBSs do Distrito Sanitário Norte

\begin{tabular}{|lc|}
\hline Características operacionais & $\%$ \\
\hline Humanização do atendimento & 100,00 \\
Família como núcleo central de abordagem & 93,10 \\
Adscrição da população sob a responsabilidade da UBS & 91,38 \\
Caráter substitutivo das práticas tradicionais exercidas nas UBSs & 91,38 \\
Abordagem multiprofissional & 84,48 \\
Estímulo às ações de promoção da saúde, à articulação intersetorial, à participação & 81,03 \\
e ao controle social & \\
Integralidade da assistência prestada à população adscrita & 79,31 \\
Acompanhamento e avaliação permanente das ações realizadas & 67,24 \\
Educação permanente dos profissionais & 46,55 \\
Articulação da referência e contrarreferência aos serviços de maior complexidade & 43,10 \\
\hline
\end{tabular}

Os percentuais encontrados demonstram que a inclusão do dentista no PSF trouxe a incorporação de novos valores e uma nova forma de prestar assistência odontológica à população do Distrito Sanitário Norte. No entanto, é preciso entender que para que o novo modelo de atenção alcance as mudanças dos saberes e práticas dos processos de trabalho em saúde esperados, as atividades das ESBs devem apresentar todas as características operacionais previstas pelo Ministério da Saúde.

Os aspectos que favorecem e os aspectos que dificultam e/ou impedem a implementação das características operacionais nas UBSs são analisados nas tabelas 2 e 3 .

Tabela 2

Aspectos que favorecem a implementação das características operacionais propostas pelo MS nas UBSs

\begin{tabular}{|c|c|c|c|}
\hline Aspecto & $\%$ & Aspecto & $\%$ \\
\hline Vínculo criado com as famílias & 43,10 & $\begin{array}{l}\text { Aç̃̃es educativas de promoção e prevenção } \\
\text { da saúde bucal }\end{array}$ & 3,45 \\
\hline Trabalho em equipe & 40,37 & Condições físicas e materiais disponíveis & 1,72 \\
\hline $\begin{array}{l}\text { Delimitação da área de atuação e do } \\
\text { número de usuários }\end{array}$ & 24,14 & Participação e controle social & 1,72 \\
\hline
\end{tabular}




\begin{tabular}{|c|c|c|c|}
\hline Aspecto & $\%$ & Aspecto & $\%$ \\
\hline Abordagem multiprofissional & 18,97 & Eleição do conselho gestor local & 1,72 \\
\hline $\begin{array}{l}\text { Educação permanente dos } \\
\text { profissionais }\end{array}$ & 18,96 & Integração da UBS com o distrito de saúde & 1,72 \\
\hline Humanização do atendimento & 15,52 & $\begin{array}{l}\text { Integração entre demais profissionais e } \\
\text { agentes comunitários de saúde }\end{array}$ & 1,72 \\
\hline $\begin{array}{l}\text { Boa vontade dos profissionais em } \\
\text { realizar o trabalho }\end{array}$ & 12,06 & $\begin{array}{l}\text { Identificação dos profissionais com a } \\
\text { filosofia do PSF }\end{array}$ & 1,72 \\
\hline Tempo de trabalho integral & 12,06 & $\begin{array}{l}\text { Concepção filosófica dos programas } \\
\text { executados na UBS }\end{array}$ & 1,72 \\
\hline $\begin{array}{l}\text { Colaboração dos agentes } \\
\text { comunitários de saúde }\end{array}$ & 8,62 & $\begin{array}{l}\text { Desmonopolização do conhecimento sobre } \\
\text { saúde }\end{array}$ & 1,72 \\
\hline Apoio institucional & 8,62 & Valorização profissional & 1,72 \\
\hline Agendamento das consultas & 6,89 & $\begin{array}{l}\text { Informatização da rede de referência em } \\
\text { odontologia }\end{array}$ & 1,72 \\
\hline $\begin{array}{l}\text { Acompanhamento e avaliação das } \\
\text { atividades }\end{array}$ & 6,89 & $\begin{array}{l}\text { Formação dos grupos de risco (idosos, } \\
\text { gestantes etc.) }\end{array}$ & 1,72 \\
\hline $\begin{array}{l}\text { Caráter substitutivo das práticas } \\
\text { tradicionais }\end{array}$ & 5,17 & $\begin{array}{l}\text { Oficinas de motivação realizadas junto aos } \\
\text { profissionais }\end{array}$ & 1,72 \\
\hline Perfil do profissional & 3,45 & Não respondeu & 1,72 \\
\hline $\begin{array}{l}\text { Criação dos centros de especialidades } \\
\text { odontológicas (CEO) }\end{array}$ & 3,45 & Corresponsabilização & 1,72 \\
\hline $\begin{array}{l}\text { Articulação da referência e } \\
\text { contrarreferência }\end{array}$ & 3,45 & $\begin{array}{l}\text { Compromisso dos profissionais com o } \\
\text { programa }\end{array}$ & 1,72 \\
\hline Integralidade da assistência & 3,45 & & \\
\hline
\end{tabular}

Como se pode observar na tabela 2, de acordo com os dentistas, o vínculo com as famílias, o trabalho em equipe, a delimitação da área de atuação, a abordagem multiprofissional, a educação permanente dos profissionais e a humanização do atendimento são os fatores que mais contribuem para que as ações de saúde bucal desenvolvidas nas UBSs apresentem as características operacionais previstas pelo MS. Convém ressaltar que todos esses aspectos estão estreitamente relacionados com o que propõe o MS para inclusão das ações de saúde bucal no PSF.

Por outro lado, pontos também importantes na filosofia do PSF como o acompanhamento e avaliação das atividades, a participação e controle social e a formação dos grupos de risco (idosos, gestantes etc.) são citados por apenas $1,72 \%$ dos dentistas. Isso faz crer que é preciso que haja um melhor planejamento e redirecionamento de algumas ações para que a proposta do PSF seja posta em prática conforme suas diretrizes. 
A tabela 3 traz os aspectos que dificultam e/ou impedem a implementação das características operacionais nas UBSs.

Tabela 3

\section{Aspectos que dificultam e/ou impedem a implementação das características operacionais propostas pelo MS nas UBSs}

\begin{tabular}{|c|c|c|c|}
\hline Aspecto & $\%$ & Aspecto & $\%$ \\
\hline $\begin{array}{l}\text { Falta de capacitação/educação } \\
\text { continuada para os profissionais }\end{array}$ & 37,93 & $\begin{array}{l}\text { Dificuldade de acesso a algumas } \\
\text { regiões da área adscrita }\end{array}$ & 3,45 \\
\hline Espaço físico inadequado & 24,14 & Não respondeu & 3,45 \\
\hline Grande demanda reprimida de pacientes & 17,24 & Falta de gerenciamento & 3,45 \\
\hline $\begin{array}{l}\text { Articulação da referência e } \\
\text { contrarreferência }\end{array}$ & 17,24 & $\begin{array}{l}\text { Falta de comunicação entre a UBS e o } \\
\text { distrito sanitário }\end{array}$ & 3,45 \\
\hline $\begin{array}{l}\text { Falta de capacitação para trabalhar em } \\
\text { grupo }\end{array}$ & 17,24 & $\begin{array}{l}\text { Ausência de rede informatizada para } \\
\text { referência em saúde bucal }\end{array}$ & 1,72 \\
\hline Ausência de profissionais de outras áreas & 12,07 & Carências da UBS & 1,72 \\
\hline $\begin{array}{l}\text { Dificuldade de substituição das práticas } \\
\text { antigas }\end{array}$ & 10,34 & Deficiência na organização dos serviços & 1,72 \\
\hline $\begin{array}{l}\text { Dificuldade de aceitação do tratamento } \\
\text { conforme o novo modelo de assistência }\end{array}$ & 8,62 & $\begin{array}{l}\text { Demora na marcação de consultas } \\
\text { referenciadas }\end{array}$ & 1,72 \\
\hline Falta de compromisso profissional & 8,62 & Perfil profissional inadequado & 1,72 \\
\hline $\begin{array}{l}\text { Demora na resolução dos problemas/ } \\
\text { atendimento das reivindicações }\end{array}$ & 6,90 & Territorialização inadequada & 1,72 \\
\hline Falta de avaliação por parte da gestão & 6,90 & $\begin{array}{l}\text { Desconhecimento dos sistemas de } \\
\text { avaliação e participação }\end{array}$ & 1,72 \\
\hline Burocracia & 6,90 & $\begin{array}{l}\text { Problemas socioeconômico-culturais da } \\
\text { comunidade }\end{array}$ & 1,72 \\
\hline Falta de material educativo & 6,90 & Sobrecarga de tarefas & 1,72 \\
\hline Localização da UBS & 5,17 & Falta de educação (visão holística) & 1,72 \\
\hline Falta de manutenção dos equipamentos & 5,17 & $\begin{array}{l}\text { Interesses da SMS voltados para os } \\
\text { níveis de produção }\end{array}$ & 1,72 \\
\hline Falta de estímulo profissional & 5,17 & $\begin{array}{l}\text { Ausência de padronização do } \\
\text { atendimento nas UBSs }\end{array}$ & 1,72 \\
\hline $\begin{array}{l}\text { Falta de apoio da SMS para algumas } \\
\text { atividades }\end{array}$ & 5,17 & Falta de planejamento local & 1,72 \\
\hline Falta de interesse da comunidade & 3,45 & & \\
\hline
\end{tabular}


Como se pode ver na tabela 3, a falta de capacitação e educação continuada para os profissionais, assim como um espaço físico inadequado para realização das atividades, a grande demanda reprimida de pacientes, a articulação da referência e contrarreferência, a falta de capacitação para trabalhar em grupo, a ausência de profissionais de outras áreas, a falta de articulação entre os componentes da equipe e a dificuldade de substituição das práticas antigas e a aceitação do novo modelo são os principais fatores que dificultam e/ou impedem a implementação das características operacionais propostas pelo MS às ações de saúde bucal no PSF.

Pode-se afirmar que na esfera do PSF a educação e a capacitação em saúde figuram como práticas previstas e atribuídas a todos os profissionais que compõem a ESB, fundamentais para a compreensão e execução de suas atividades. Todavia, é preciso que não só os profissionais que lidam com a odontologia participem desse processo. É essencial o relacionamento com os demais profissionais da equipe de saúde da família e o trabalho de conscientização das famílias para que os novos padrões cognitivos e culturais sejam assimilados.

É preciso ressaltar também que alguns aspectos menos citados pelos dentistas como a falta de apoio da SMS para algumas atividades $(5,17 \%)$, a falta de comunicação entre a UBS e o distrito sanitário (3,45\%), a dificuldade de acesso a algumas regiões da área adscrita $(3,45 \%)$ e a falta de planejamento local $(1,72 \%)$ são aspectos que têm relação direta com a execução das atividades de saúde bucal nas UBSs exigindo atenção especial.

A figura 1 revela a avaliação que os dentistas fazem sobre as suas condições de trabalho com relação ao ambiente físico. Para essa questão utilizou-se a seguinte escala de respostas: muito boa, boa, razoável, ruim e muito ruim.

Como se pode observar, $37,93 \%$ dos dentistas consideram a sua condição de trabalho com relação ao ambiente físico apenas razoável; 10,34\% consideram ruim; e $18,97 \%$ consideram muito ruim. Isso explica o fato de as condições físicas inadequadas terem sido apontadas pelos dentistas como um fator que dificulta a implementação tanto das características operacionais quanto das atribuições profissionais previstas pelo MS. Enquanto isso, apenas $32,76 \%$ dos dentistas consideram muito boa, ou boa, a sua condição de trabalho em relação ao ambiente físico.

Para compreender melhor a questão, a tabela 4 indica quais fatores interferem positivamente no desempenho das atividades dos dentistas com relação a esse aspecto. 


\section{Figura 1}

\section{Avaliação das condições de trabalho em relação ao ambiente físico}

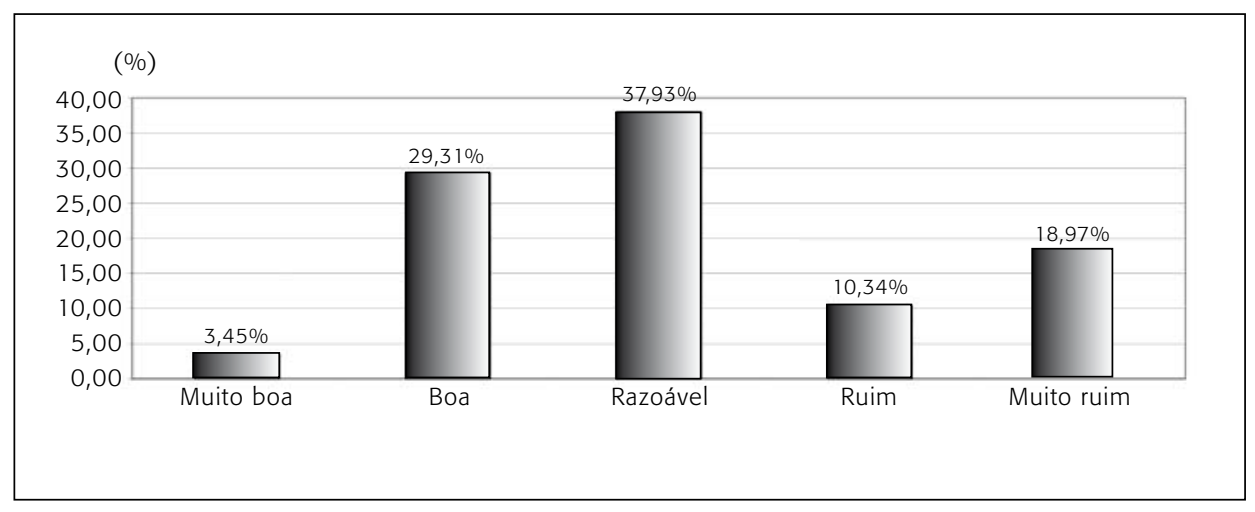

Tabela 4

Fatores que interferem positivamente nas condições de trabalho dos dentistas com relação ao ambiente físico

\begin{tabular}{|lrlc|}
\hline Fator & $\%$ & \multicolumn{1}{c|}{ Fator } & $\%$ \\
\hline Ter ar-condicionado & 39,66 & Desempenho auxiliar de consultório dentário & 5,17 \\
Não respondeu & 25,86 & Ambiente adaptado ao PSF & 3,45 \\
Equipamento novo e de boa & 22,41 & Limpeza do ambiente & 3,45 \\
qualidade & & & \\
Tamanho do consultório & 20,69 & Boa relação com os colegas de trabalho & 3,45 \\
Instalações novas & 15,52 & Esterilização na UBS & 3,45 \\
lluminação do ambiente & 8,62 & Escovódromo com espelhos & 3,45 \\
Localização da UBS & 8,62 & Supervisão da Covisa & 1,72 \\
Instrumental novo & 8,62 & Material de boa qualidade & 1,72 \\
Nenhum & 5,17 & Agendamento do atendimento & 1,72 \\
\hline
\end{tabular}

Com base nas respostas acima se pode dizer que na opinião dos dentistas o principal fator positivo com relação ao ambiente físico é a refrigeração do ar por meio do ar-condicionado. Além disso, um percentual de $22,41 \%$ dos dentistas refere-se ao estado de conservação e à qualidade dos equipamentos, e 20,69\% ao tamanho do consultório. Observa-se que um percentual elevado de $25,86 \%$ dos profissionais não respondeu a essa questão deixando de contribuir para uma melhor compreensão desse aspecto. E, ainda, que aspectos 
como iluminação, localização e limpeza do local de trabalho são citados pelos profissionais mesmo que com baixos percentuais.

A tabela 5 traz os fatores que interferem negativamente no desempenho das atividades dos dentistas com relação ao ambiente físico.

Tabela 5

Fatores que interferem negativamente nas condições de trabalho dos dentistas com relação ao ambiente físico

\begin{tabular}{|c|c|c|c|}
\hline Fator & $\%$ & Fator & $\%$ \\
\hline Estrutura física inadequada & 98,29 & $\begin{array}{l}\text { Demora nas resoluções dos } \\
\text { problemas }\end{array}$ & 1,72 \\
\hline $\begin{array}{l}\text { Falta de espaço para as aç̃̃es } \\
\text { educativas }\end{array}$ & 29,31 & Equipamento velho & 1,72 \\
\hline $\begin{array}{l}\text { Salas sem divisórias (dois } \\
\text { consultórios no mesmo local) }\end{array}$ & 22,41 & Um consultório para dois dentistas & 1,72 \\
\hline $\begin{array}{l}\text { Manutenção ineficiente dos } \\
\text { equipamentos }\end{array}$ & 15,51 & Vazamentos d'água & 1,72 \\
\hline Falta de limpeza no ambiente & 12,07 & $\begin{array}{l}\text { Falta de espelho para orientação à } \\
\text { escovação }\end{array}$ & 1,72 \\
\hline Não respondeu & 13,79 & Esterilização fora da UBS & 1,72 \\
\hline Falta de frigobar & 3,45 & Problemas de relacionamento pessoal & 1,72 \\
\hline Localização da UBS & 3,45 & Falta de valorização profissional & 1,72 \\
\hline $\begin{array}{l}\text { Falta de instrumental, material e } \\
\text { equipamento }\end{array}$ & 3,44 & & \\
\hline
\end{tabular}

Na tabela 5, a estrutura física inadequada é mais uma vez citada. Aqui ela é identificada por $98,29 \%$ dos dentistas como o fator negativo que mais influencia suas condições de trabalho com relação ao ambiente físico. Isso se deve ao fato de que algumas dessas UBSs estão localizadas em espaços que foram reaproveitados, assim muitas não possuem sequer um local para as reuniões da equipe. Outro ponto importante, citado por $29,31 \%$ dos profissionais, é a falta de espaço para as ações educativas. Muitas UBSs não têm, por exemplo, um escovódromo, que seria o local adequado para, entre outras coisas, ensinar o paciente a maneira correta de escovação dos dentes. Com isso, parece claro afirmar que as UBSs, em sua grande maioria, estão estabelecidas em locais que não dispõem de uma estrutura física adequada para a realização das atividades previstas aos dentistas no PSF.

Aqui, aspectos relacionados à limpeza e à localização do local de trabalho foram novamente citados. Outro ponto que também merece atenção é a falta de divisórias nas salas que são ocupadas por dois consultórios. 
A figura 2 avalia as condições de trabalho com relação à disponibilidade de equipamentos e insumos, a partir de uma escala com as seguintes alternativas: muito boa, boa, razoável, ruim e muito ruim.

\section{Figura 2}

Avaliação das condições de trabalho em relação à disponibilidade de equipamentos e insumos

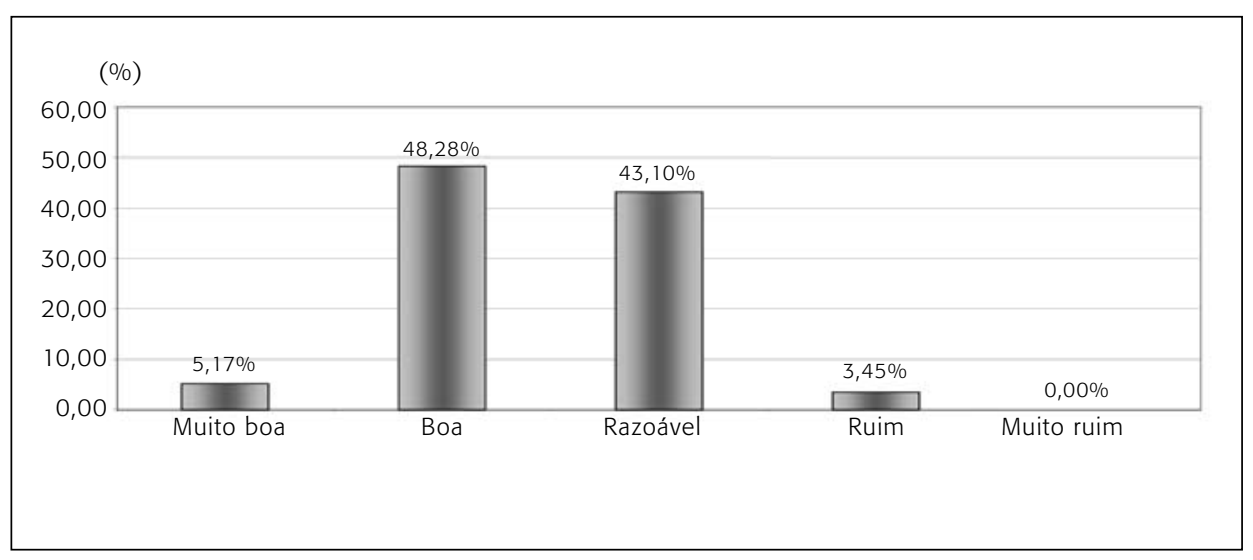

Percebe-se que para a grande maioria dos dentistas, 91,38\%, as condições de trabalho em relação à disponibilidade de equipamentos e insumos é boa ou razoável. Esse fato é contraditório com argumentos anteriores apresentados, pois os dentistas se referem à falta de material para as ações preventivas e educativas como um dos aspectos que dificulta a realização de suas atribuições profissionais nas UBSs.

Para essa avaliação os aspectos que interferem positivamente segundo os dentistas estão evidenciados na tabela 6.

Como se constata na tabela 6 , a presença de equipamentos novos e com boa manutenção, bem como a regularidade na reposição de material são os fatores positivos mais importantes sob esse aspecto das condições de trabalho. Observa-se também que a boa qualidade do material de consumo e a disponibilidade de instrumentais novos são fatores relevantes nesse sentido. Convém ressaltar ainda que $22,42 \%$ dos dentistas não responderam a essa questão e que para um pequeno percentual de dentistas a existência de equipamentos de proteção individual (máscaras, luvas, gorros, entre outros) satisfatórios é um fator importante. 
Tabela 6

Aspectos que interferem positivamente nas condições de trabalho dos dentistas com relação à disponibilidade de equipamentos e insumos

\begin{tabular}{|lrlc|}
\hline Aspecto & \multicolumn{1}{c}{ Aspecto } & $\%$ \\
\hline $\begin{array}{l}\text { Equipamentos novos/com boa } \\
\text { manutenção }\end{array}$ & 37,93 & Boa qualidade do instrumental & 6,90 \\
$\begin{array}{l}\text { Regularidade e controle na reposição de } \\
\text { material }\end{array}$ & 36,21 & $\begin{array}{l}\text { Equipamentos de proteção individual } \\
\text { Não respondeu }\end{array}$ & 3,45 \\
$\begin{array}{l}\text { Material de boa qualidade } \\
\text { Instrumentais novos }\end{array}$ & 22,42 & Empenho dos profissionais & 1,72 \\
$\begin{array}{l}\text { Materiais e equipamentos permitem } \\
\text { agilidade no tratamento }\end{array}$ & 18,97 & Nenhum & 1,72 \\
\hline
\end{tabular}

A tabela 7 informa os aspectos relacionados aos equipamentos e insumos que interferem negativamente na realização das atividades nas UBSs.

Tabela 7

Aspectos que interferem negativamente nas condições de trabalho dos dentistas com relação à disponibilidade de equipamentos e insumos

\begin{tabular}{|c|c|c|c|}
\hline Aspecto & $\%$ & Aspecto & $\%$ \\
\hline $\begin{array}{l}\text { Manutenção demorada e ineficiente dos } \\
\text { equipamentos }\end{array}$ & 34,48 & Problemas de relação pessoal & 3,45 \\
\hline Falta de material & 22,41 & $\begin{array}{l}\text { Burocracia no atendimento das } \\
\text { necessidades }\end{array}$ & 3,44 \\
\hline Não respondeu & 20,69 & Alguns materiais de qualidade ruim & 3,45 \\
\hline Estrutura física inadequada & 13,79 & $\begin{array}{l}\text { Equipamentos de proteção individual } \\
(\mathrm{EPI}) \text { de qualidade ruim }\end{array}$ & 1,72 \\
\hline Falta de equipamentos & 8,62 & $\begin{array}{l}\text { Mesmo compressor utilizado pelos } \\
\text { dentistas e para nebulizações }\end{array}$ & 1,72 \\
\hline Esterilização fora da UBS & 8,62 & Equipamentos velhos & 1,72 \\
\hline Instrumental insuficiente & 5,17 & Ausência de farmácia odontológica & 1,72 \\
\hline $\begin{array}{l}\text { Problemas com a energia elétrica (sistema } \\
\text { bifásico) }\end{array}$ & 3,45 & $\begin{array}{l}\text { Deficiências relacionadas às ações } \\
\text { educativas }\end{array}$ & 1,72 \\
\hline
\end{tabular}

Para essa avaliação, a manutenção demorada e ineficiente dos equipamentos e a falta de material são os fatores negativos mais mencionados pelos dentistas. Outros dois pontos que devem ser considerados importantes são a 
falta de equipamentos e a esterilização fora das UBSs citados por 8,62\% dos profissionais. É preciso ressaltar ainda que 20,69\% dos dentistas também não responderam a essa questão.

A figura 3 mostra a avaliação dos dentistas sobre as suas condições de trabalho no que se refere à autonomia e ao seu poder de decisão, a partir da seguinte escala: muito boa, boa, razoável, ruim e muito ruim.

\section{Figura 3}

Avaliação das condições de trabalho no que se refere à autonomia e ao poder de decisão dos dentistas

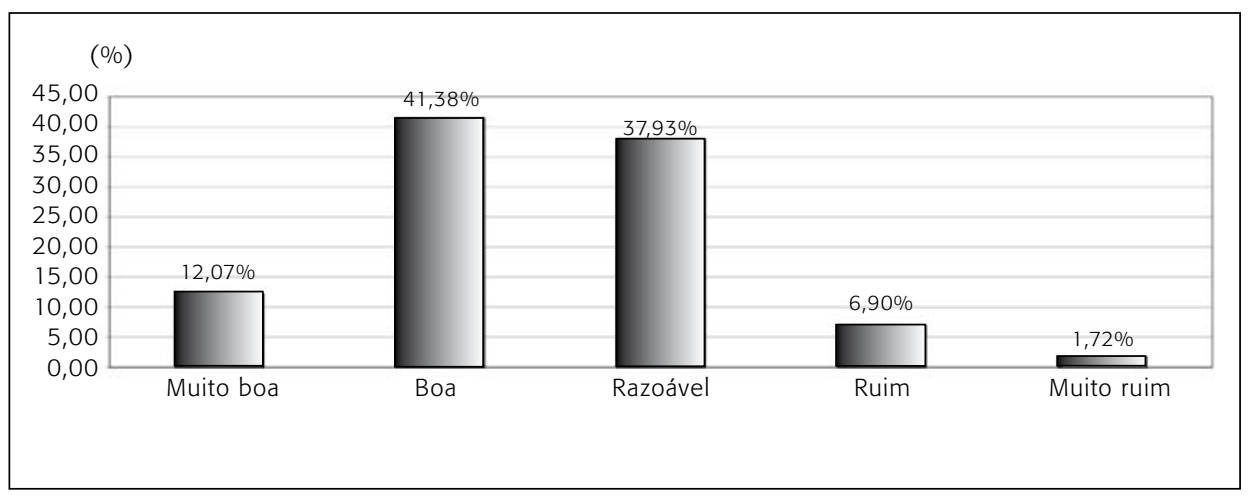

Com relação a esse aspecto, um percentual elevado de profissionais, $79,31 \%$, avaliam a sua condição de trabalho como boa ou razoável. Isso significa que os dentistas das UBSs do Distrito Sanitário Norte têm liberdade de atuar e decidir sob aspectos do seu trabalho, agilizando e facilitando o desenvolvimento de suas atividades. Esse fato é um aspecto positivo para a realização das ações de saúde bucal nas UBSs do PSF do Distrito Sanitário Norte.

Os fatores que interferem positivamente na opinião dos dentistas estão na tabela 8 .

Observa-se que 20,69\% dos dentistas não responderam a essa questão. Para os que responderam, a liberdade de fazer a própria agenda, o bom relacionamento das equipes e a facilidade de acesso ao gerente e ao supervisor do distrito são os fatores positivos mais importantes. A autonomia e o poder de decisão dos dentistas nas UBSs implica menos burocracia e maior facilidade de execução para algumas atividades. Esse fato é um aspecto que contribui para agilizar o desenvolvimento das atividades nas UBSs, importante para o programa. 
Tabela 8

Fatores que interferem positivamente nas condições de trabalho dos dentistas com relação à autonomia e ao poder de decisão

\begin{tabular}{|lrlc|}
\hline Fator & $\%$ & \multicolumn{1}{c}{ Fator } & $\%$ \\
\hline Agenda feita pelo próprio dentista & 31,03 & Motivação da equipe & 3,45 \\
Bom relacionamento das equipes & 22,41 & Nenhum & 3,45 \\
Não respondeu & 20,69 & Planejamento em equipe & 1,72 \\
Facilidade de acesso ao gerente e & 12,07 & Apoio dos ACSs e funcionários das & 1,72 \\
supervisor do distrito & & UBSs & \\
Planejamento do trabalho & 8,62 & Tranquilidade de trabalho & 1,72 \\
$\begin{array}{l}\text { Decisões tomadas por toda equipe } \\
\text { Mais agilidade e facilidade no }\end{array}$ & 8,62 & Vínculo com a população & 1,72 \\
desenvolvimento de projetos & 10,34 & Maior facilidade de acolhimento de & 1,72 \\
Compromisso profissional & & sugestões & \\
\hline
\end{tabular}

A tabela 9 traz os fatores relacionados à autonomia e ao poder de decisão que interferem negativamente na execução das atividades das UBSs.

Tabela 9

Fatores que interferem negativamente nas condições de trabalho dos dentistas com relação à autonomia e ao poder de decisão

\begin{tabular}{|lrlr|}
\hline Fator & $\%$ & \multicolumn{1}{c}{ Fator } & $\%$ \\
\hline Não respondeu & 46,55 & Sobrecarga de tarefas & 1,72 \\
Autonomia não é suficiente para decidir & 12,07 & Acúmulo de funções & 1,72 \\
Entraves burocráticos & 8,62 & Competitividade entre profissionais & 1,72 \\
Falta de articulação entre profissionais e & 6,90 & Comodismo & 1,72 \\
gestores & & & 1,72 \\
Dificuldade na resolução dos problemas & 5,17 & Problemas de autoestima & 1,72 \\
Médicos e enfermeiras têm maior & 5,17 & Falta de preparo para controle social & \\
credibilidade & & & 1,72 \\
Falta de integração da equipe & 5,17 & Ausência de equidade & 1,72 \\
Centralização de conhecimentos & 3,45 & Ausência de gerenciamento & 1,72 \\
Individualização do atendimento & 3,45 & Falta de apoio do distrito & 1,72 \\
Não ter recursos financeiros próprios & 3,45 & Flexibilidade do horário de & atendimento \\
\hline
\end{tabular}


Como se pode perceber, mais uma vez, um grande número de dentistas, 46,55\%, não à questão, tornando difícil uma melhor compreensão desse aspecto de suas condições de trabalho. Ainda assim, como fator negativo mais citado surge o fato de que a "autonomia não é suficiente para decidir". Logo, pode-se dizer que a liberdade de atuação que os dentistas têm se restringe apenas a determinados aspectos de seu trabalho, como elaborar a agenda de atendimento. Outro ponto interessante apontado por $5,17 \%$ dos profissionais é o fato de "médicos e enfermeiras terem maior credibilidade". Por terem sido incluídos depois desses profissionais no PSF, os dentistas não têm ainda seu espaço bem definido nas ESFs.

A figura 4 indica a avaliação que os dentistas fazem sobre a integração da equipe de saúde bucal com a equipe de saúde da família na unidade básica de saúde em que trabalham, a partir da seguinte escala: muito boa, boa, razoável, ruim e muito ruim.

Figura 4

\section{Avaliação da integração ESB com a ESF}

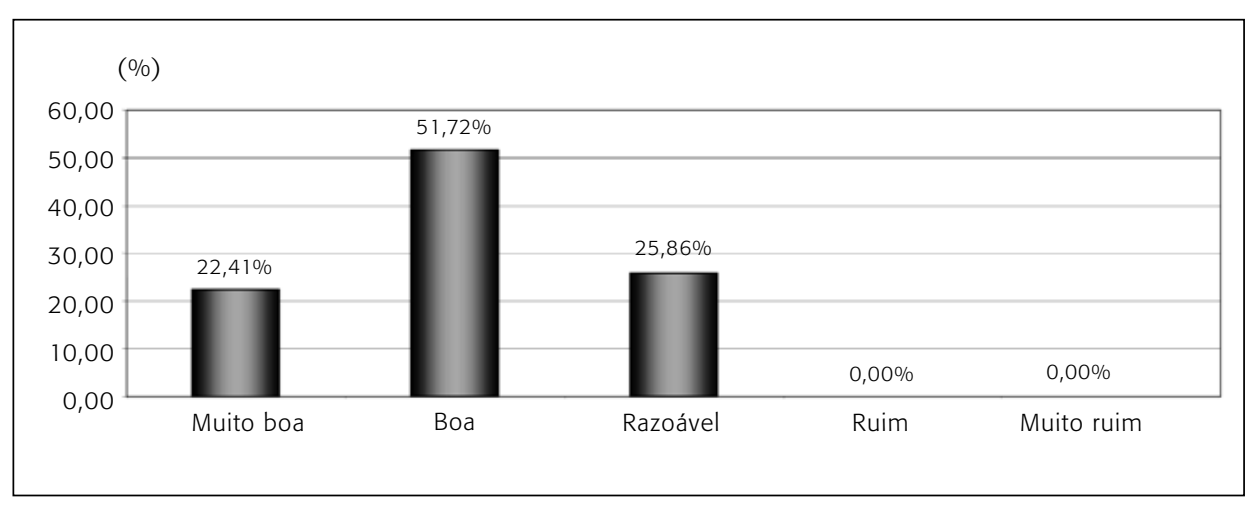

Para 51,72\% dos dentistas, a integração entre a ESB e a ESF é boa, para $22,41 \%$ muito boa e para $25,86 \%$ razoável. A integração das ESBs com as ESFs pode ser vista como fator positivo na condução das atividades das UBSs no Distrito Sanitário Norte por promover a prática tanto de ações coletivas como a de ações intersetoriais, bem como a abordagem multiprofissional, pontos importantes na filosofia de assistência à saúde trazida pelas diretrizes do PSF.

De acordo com a tabela 10, o bom relacionamento pessoal é o aspecto que mais contribui para isso. Além disso, a realização de atividades em equipe, o planejamento das ações em grupo e a disponibilidade dos membros da equi- 
pe são também fatores positivos para integração da ESB com a ESF na opinião dos dentistas. Percebe-se que muitos outros aspectos foram citados pelos dentistas, entretanto parecem percepções isoladas sem grande representatividade para a questão.

Tabela 10

Aspectos que interferem positivamente na integração da ESB com a ESF

\begin{tabular}{|c|c|c|c|}
\hline Aspecto & $\%$ & Aspecto & $\%$ \\
\hline Bom relacionamento pessoal & 39,65 & Desenvolvimento das atividades & 1,72 \\
\hline Disponibilidade dos membros da equipe & 25,86 & Realização das ações preventivas & 1,72 \\
\hline Planejamento das ações em grupo & 18,97 & $\begin{array}{l}\text { Acompanhamento de grupos } \\
\text { específicos }\end{array}$ & 1,72 \\
\hline $\begin{array}{l}\text { Atividades em que toda a equipe está } \\
\text { reunida }\end{array}$ & 12,07 & $\begin{array}{l}\text { Melhoria na qualidade de vida da } \\
\text { população }\end{array}$ & 1,72 \\
\hline Equipe com objetivos comuns & 8,62 & $\begin{array}{l}\text { Aproximação entre profissionais e } \\
\text { famílias }\end{array}$ & 1,72 \\
\hline Melhor assistência à população & 8,62 & Experiência profissional & 1,72 \\
\hline Compromisso profissional & 8,62 & Equipe completa & 1,72 \\
\hline Não respondeu & 8,62 & Preceitos filosóficos do programa & 1,72 \\
\hline $\begin{array}{l}\text { Participação da ESB em atividades com } \\
\text { outros profissionais }\end{array}$ & 5,17 & Valorização profissional & 1,72 \\
\hline $\begin{array}{l}\text { População atendida ser comum a todos os } \\
\text { profissionais }\end{array}$ & 3,45 & Mudança de prática & 1,72 \\
\hline Igualdade de tratamento & 3,45 & $\begin{array}{l}\text { Pequena quantidade de } \\
\text { profissionais }\end{array}$ & 1,72 \\
\hline Ambiente de trabalho & 3,45 & & \\
\hline
\end{tabular}

A tabela 11 traz a opinião dos dentistas sobre os aspectos que interferem negativamente na integração das ESBs com as ESFs.

Observa-se que $37,93 \%$ dos dentistas não responderam quando perguntados sobre os fatores negativos relacionados a essa questão. Mas fatores como a falta de afinidade, a falta de alguns profissionais na equipe, a falta de capacitação para o trabalho em equipe, a falta de compromisso de alguns membros e a pequena quantidade de atividades realizadas em conjunto estão entre os fatores mais apontados pelos dentistas. A incompatibilidade de horários das atividades, citada por $3,45 \%$ dos profissionais, e a falta de promoção intersetorial, citada por $1,72 \%$, também merecem destaque. 
Tabela 11

\section{Aspectos que interferem negativamente na integração da ESB com a ESF}

\begin{tabular}{|c|c|c|c|}
\hline Aspecto & $\%$ & Aspecto & $\%$ \\
\hline Não respondeu & 37,93 & $\begin{array}{l}\text { Práticas muito centradas nas ações } \\
\text { curativas }\end{array}$ & 1,72 \\
\hline Falta de afinidade & 10,34 & Falta de promoção intersetorial & 1,72 \\
\hline Falta de profissionais na equipe & 8,62 & $\begin{array}{l}\text { Reuniões conjuntas realizadas em más } \\
\text { condições devido à estrutura física da } \\
\text { UBS }\end{array}$ & 1,72 \\
\hline $\begin{array}{l}\text { Falta de capacitação para o trabalho em } \\
\text { equipe }\end{array}$ & 6,90 & Interferências pessoais & 1,72 \\
\hline $\begin{array}{l}\text { Falta de compromisso de alguns } \\
\text { membros da equipe }\end{array}$ & 5,17 & $\begin{array}{l}\text { Obrigatoriedade do cumprimento dos } \\
\text { horários }\end{array}$ & 1,72 \\
\hline Prioridades não são comuns a todos & 5,17 & $\begin{array}{l}\text { Alguns profissionais não conhecem a } \\
\text { área de trabalho }\end{array}$ & 1,72 \\
\hline Poucas atividades em conjunto & 5,17 & $\begin{array}{l}\text { Equipe não costuma planejar em } \\
\text { conjunto }\end{array}$ & 1,72 \\
\hline $\begin{array}{l}\text { Grande demanda de pacientes por } \\
\text { equipe }\end{array}$ & 5,17 & Isolamento da odontologia & 1,72 \\
\hline $\begin{array}{l}\text { Falta de adaptação ao novo modelo de } \\
\text { saúde }\end{array}$ & 3,45 & Dificuldades no desempenho das ações & 1,72 \\
\hline $\begin{array}{l}\text { Falta de adaptação entre os ACSs e } \\
\text { demais profissionais }\end{array}$ & 3,45 & Formação de subequipes & 1,72 \\
\hline $\begin{array}{l}\text { Incompatibilidade de horários das } \\
\text { atividades }\end{array}$ & 3,45 & Falta de supervisão & 1,72 \\
\hline Falta de credibilidade dos dentistas & 3,45 & Fofocas & 1,72 \\
\hline Individualismo de alguns profissionais & 3,44 & Condições materiais & 1,72 \\
\hline $\begin{array}{l}\text { Falta de comunicação entre os } \\
\text { membros da equipe devido ao grande } \\
\text { número de atendimentos clínicos }\end{array}$ & 3,44 & & \\
\hline
\end{tabular}

A figura 5 revela a avaliação que os dentistas fazem da realização das ações de saúde bucal nas UBSs que trabalham, a partir de uma escala com as seguintes alternativas: muito boa, boa, razoável, ruim e muito ruim.

Como pôde ser visto na figura 5 , a realização das ações de saúde bucal nas UBSs do Distrito Sanitário Norte é avaliada como boa por $58,62 \%$ dos dentistas e como muito boa por 17,24\%. Esse fato serve de estímulo e motivação para os dentistas que veem no PSF uma nova fonte de emprego em expansão no Brasil. 


\section{Figura 5}

\section{Avaliação das ações de saúde bucal nas UBSs}

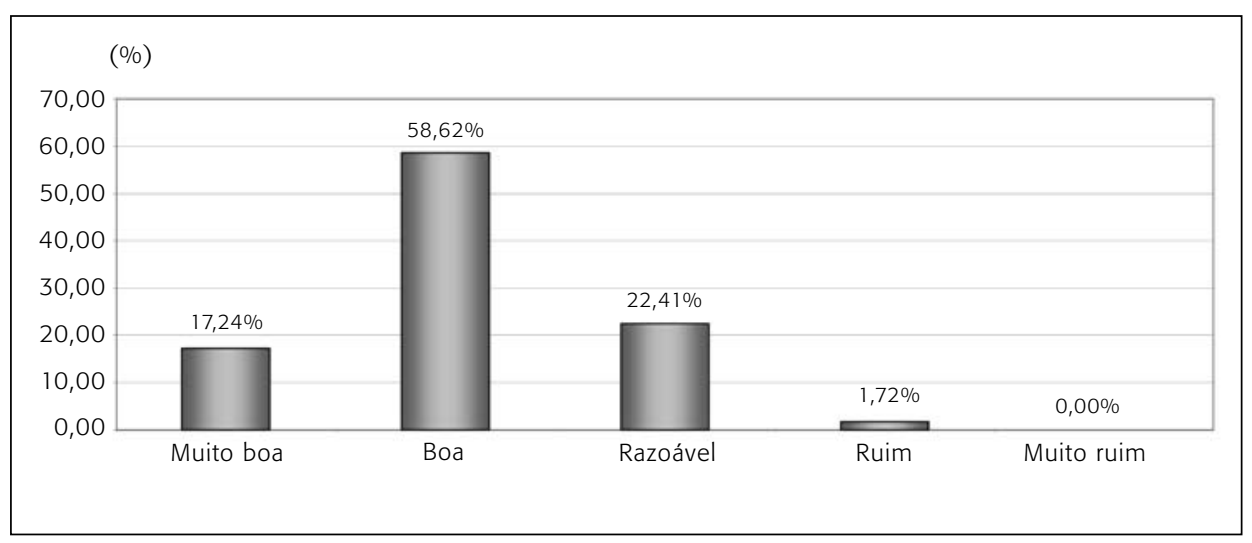

Conforme a tabela 12, a capacidade profissional, a integração da equipe, a cooperação da comunidade, bem como o compromisso e a boa vontade dos profissionais são os aspectos que mais favorecem esse resultado. Outros pontos menos citados como a disponibilidade de material, instrumental e equipamentos, o planejamento das atividades e o horário de atendimento integral também devem ser ressaltados pela sua importância para essa questão.

Tabela 12

\section{Aspectos que interferem positivamente na realização das ações de saúde bucal nas UBSs}

\begin{tabular}{|lrlc|}
\hline Aspecto & $\%$ & \multicolumn{1}{c}{ Aspecto } & $\%$ \\
\hline Capacidade profissional & 46,55 & Disponibilidade de instrumental & 3,45 \\
Integração da equipe & 44,84 & Rodas de conversa & 1,72 \\
Cooperação da comunidade & 29,30 & Horário integral de atendimento & 1,72 \\
Compromisso e boa vontade dos & 20,69 & Estrutura física & 1,72 \\
profissionais & & & \\
Não respondeu & 13,79 & Atendimento das urgências & 1,72 \\
Ações preventivas e educativas & 12,07 & Ações curativas & 1,72 \\
Disponibilidade e qualidade do material & 10,34 & Adscrição da população & 1,72 \\
Disponibilidade de equipamentos & 8,62 & Apoio da coordenação, do distrito e & 1,72 \\
& & da SMS & 1,72 \\
Tratamento continuado & 6,90 & Conscientização profissional & Continua
\end{tabular}




\begin{tabular}{|lllc|}
\hline Aspecto & $\%$ & \multicolumn{1}{c|}{ Aspecto } & $\%$ \\
\hline Vínculo com a população & 5,17 & Humanização do atendimento & 1,72 \\
Planejamento das atividades & 5,17 & Flúor à vontade e escovas & 1,72 \\
Realização do tratamento completo do & 5,17 & & \\
paciente & & & \\
\hline
\end{tabular}

Com relação aos aspectos que interferem negativamente na realização das ações de saúde bucal nas UBSs, observa-se na tabela 13 que $32,76 \%$ dos dentistas não responderam. No entanto, $20,69 \%$ apontam novamente a falta de uma estrutura física adequada como um fator prejudicial à realização das atividades no PSF. Além disso, 17,24\% referem-se à grande demanda reprimida de pacientes, $15,52 \%$ à falta de material educativo, $13,78 \%$ à falta de entrosamento entre os profissionais e 6,90\% à dificuldade de compreensão do novo modelo de assistência e a falta de manutenção dos equipamentos.

$$
\text { Tabela } 13
$$

\section{Aspectos que interferem negativamente na realização das ações de saúde bucal nas UBSs}

\begin{tabular}{|lrlc|}
\hline Aspecto & $\%$ & \multicolumn{1}{c}{ Aspecto } & $\%$ \\
\hline Não respondeu & 32,76 & Falta de incentivo aos profissionais & 1,72 \\
Estrutura física inadequada & 20,69 & Insatisfação da população não atendida & 1,72 \\
Grande demanda reprimida & 17,24 & Falta de trabalho coletivo & 1,72 \\
Falta de material educativo & 15,52 & Acúmulo de funções & 1,72 \\
Falta de entrosamento entre os & 13,78 & Não formação dos grupos específicos & 1,72 \\
profissionais & & & \\
Dificuldade de compreensão do novo & 6,90 & Dificuldades nas resoluções dos & 1,72 \\
modelo de assistência à saúde & & problemas & \\
Falta de manutenção dos equipamentos & 6,90 & Falta de material & 1,72 \\
Localização da UBS & 5,17 & Falta de interesse profissional & 1,72 \\
Falta de interesse e conhecimento por & 5,17 & Falta de credibilidade dos dentistas & 1,72 \\
parte da população & & & 1,72 \\
Ausência de supervisão e avaliação & 1,72 & Falta de planejamento & 1,72 \\
Baixa autoestima & 1,72 & Falta de promoção intersetorial & \\
Fofocas & 1,72 & & \\
\hline
\end{tabular}

A figura 6 aponta a avaliação dos dentistas sobre a inclusão das ações de saúde bucal no PSF, a partir da escala a seguir: muito boa, boa, razoável, ruim e muito ruim. 
Figura 6

Avaliação da inclusão das ações de saúde bucal no PSF

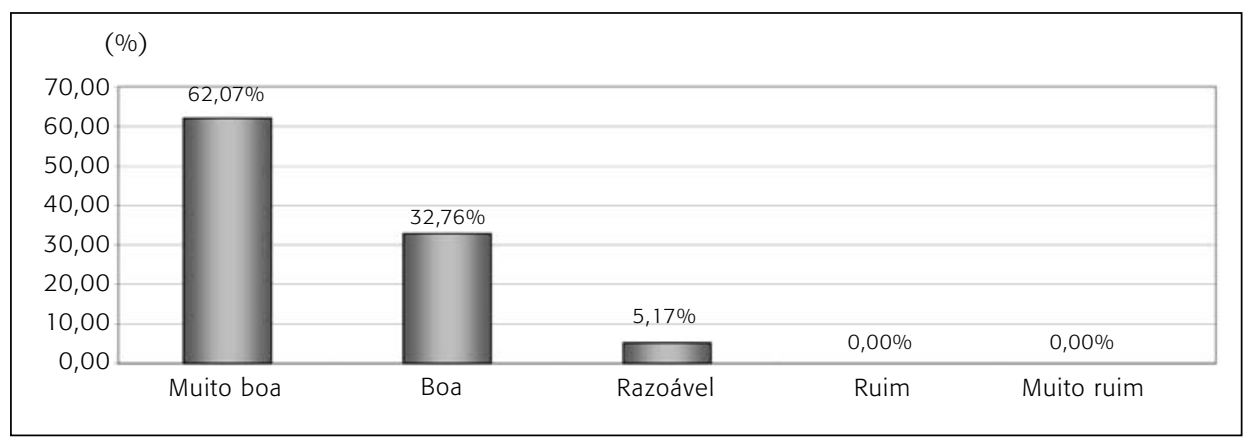

Verifica-se que para $62,07 \%$ dos dentistas a inclusão das ações de saúde bucal no PSF é avaliada como muito boa e para 32,76\% boa; apenas 5,17\% consideram razoável. Uma questão que vem sendo discutida na atualidade diz respeito ao mercado de trabalho que se abriu para a categoria odontológica com a inclusão da saúde bucal no PSF.

A figura 7 indica a avaliação que os dentistas fazem sobre as mudanças causadas pela inclusão das ações de saúde bucal no PSF do Distrito Sanitário Norte de Natal, RN, a partir da seguinte escala: muito boa, boa, razoável, ruim e muito ruim.

\section{Figura 7}

Avaliação das mudanças causadas pela inclusão das ações de saúde bucal no PSF do Distrito Sanitário Norte de Natal, RN

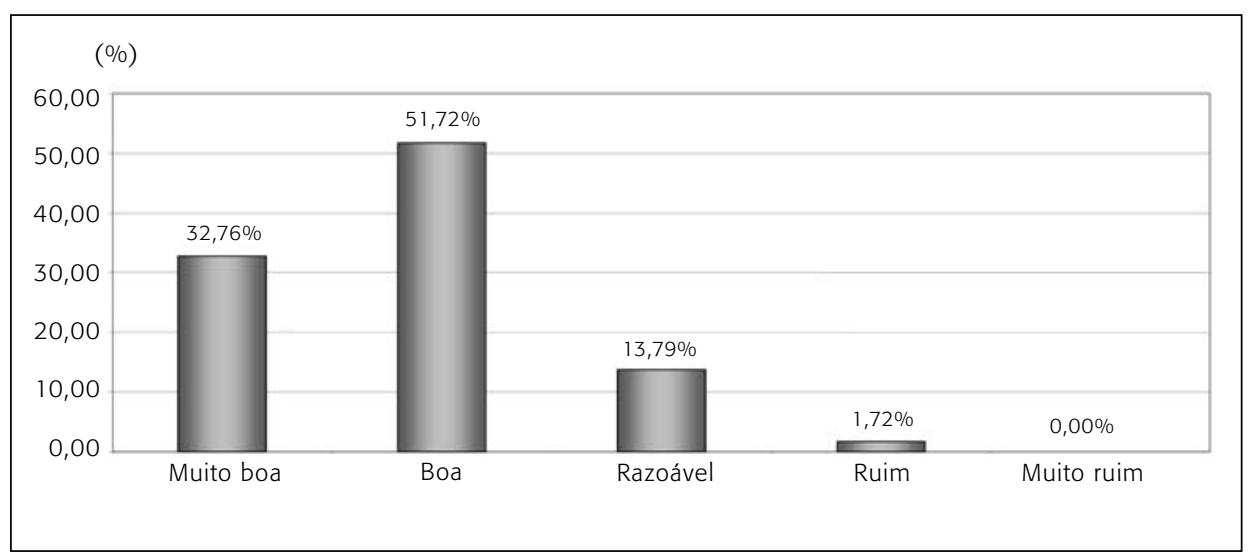


De acordo com a figura 7, 51,72\% dos dentistas avaliam as mudanças causadas pela inclusão das ações de saúde bucal no PSF do Distrito Sanitário Norte como boas, $32,76 \%$ avaliam como muito boas e $13,79 \%$ como razoáveis. Com isso, pode-se dizer que o PSF vem conseguindo imprimir um novo cenário no que diz respeito à saúde bucal da população do Distrito Sanitário Norte na medida em que tem ampliado o acesso da população por meio de um novo modelo de assistência à saúde.

A figura 8 retrata a opinião dos dentistas a respeito de qual seria a reação da população caso as ações de saúde bucal fossem extintas do PSF, a partir de uma escala cujas alternativas são: muito boa, boa, razoável, ruim e muito ruim.

Figura 8

Opinião dos dentistas a respeito da reação da população caso as ações de saúde bucal fossem extintas do PSF

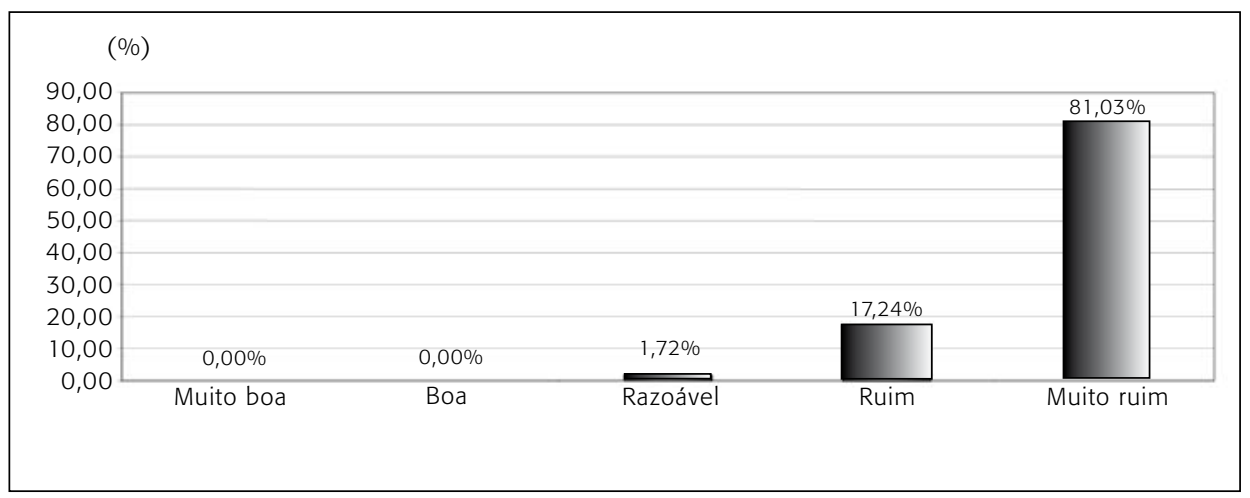

Como se pode observar, 81,03\% dos dentistas lotados nas UBSs do Distrito Sanitário Norte acreditam que a população reagiria de modo muito ruim caso isso acontecesse. Tal avaliação pode sugerir que a inclusão das ESBs no PSF do Distrito Sanitário Norte tem conseguido ampliar o acesso da população às ações de saúde bucal, suprindo melhor a grande carência da comunidade, razão pela qual ela reagiria negativamente a uma proposta de extinção do programa.

De acordo com o que foi visto, reafirma-se a necessidade de avaliação das atividades desenvolvidas pelas ESBs, demonstrando ser fundamental acompanhar os dados para que eles sirvam de base para o planejamento e redirecionamento das ações. 


\section{Conclusão}

Este artigo verificou as condições de trabalho dos dentistas das equipes de saúde bucal (ESBs) do Programa Saúde da Família (PSF) do Distrito Sanitário Norte de Natal-RN.

Conforme o Ministério da Saúde (MS), a inclusão das ações de saúde bucal na estratégia de saúde da família deverá expressar os princípios e diretrizes do SUS, e ser pautadas pela universalidade, integralidade e equidade, organizadas de maneira descentralizada, hierarquizada e com a participação da população. Para isso, o MS através da Portaria no 267 instituiu as características operacionais que as ações de saúde bucal devem apresentar no PSF e as atribuições dos profissionais de saúde bucal no PSF.

$\mathrm{O}$ artigo revelou, por meio de pesquisa, que muitas atividades realizadas pelos dentistas nas ESBs do Distrito Sanitário Norte não estão de acordo com essa orientação.

Aspectos como a articulação da referência e contrarreferência que diz respeito a encaminhar e orientar os usuários com problemas mais complexos a outros níveis de especialização, assegurando o seu retorno e acompanhamento, inclusive para fins de complementação do tratamento, não têm funcionado como o previsto, tanto pelo não atendimento das especialidades quanto pela falta de especialistas nas UBSs. Com isso, a integralidade da assistência prestada à população adscrita deixa de ser exercida pelos dentistas e, assim, as famílias não têm suas necessidades e expectativas atendidas.

Outro ponto importante se refere à educação permanente dos profissionais. Os dentistas têm perfil profissional voltado para a clínica, o que está relacionado à sua formação acadêmica. Esse perfil clínico preponderante vai de encontro a características identificadas como imprescindíveis ao trabalho no PSF: ter um conhecimento amplo e multidisciplinar; ter habilidade para atender a diferentes tipos de demandas; gostar de trabalhar com comunidades pobres; trabalhar em equipe.

Não é por acaso que muitos dentistas destacaram a pouca disponibilidade dos cursos de capacitação como um aspecto negativo nas atividades do PSF do Distrito Sanitário Norte, enfatizando a sua necessidade e importância.

Espera-se que a ESB esteja capacitada para dar assistência integral e contínua às famílias da área adscrita, identificando situações de risco à saúde na comunidade assistida para enfrentar, em parceria com a comunidade, os determinantes do processo saúde-doença, e desenvolver processos educativos para a saúde voltados à melhoria do autocuidado dos indivíduos. Isso remete às atividades de promoção e prevenção, pilares fundamentais do modelo de assistência proposto pelo PSF e também à necessidade de sensibilização das famílias assisti- 
das. Entretanto, nas UBSs do Distrito Sanitário Norte predomina a realização de atividades de caráter puramente curativo como restaurações e exodontias.

Atividades relacionadas ao desenvolvimento de ações que promovam a intersetorialidade, como programar e supervisionar o fornecimento de materiais e insumos para ações coletivas, capacitar as ESFs no que se refere às ações educativas e preventivas em saúde bucal, parecem não ter tanta importância para os dentistas que trabalham nas UBSs do Distrito Sanitário Norte. O mesmo ocorre com as atividades relacionadas à realidade epidemiológica da saúde bucal da população adscrita. Assim, os dentistas deixam de contemplar orientações previstas pelo MS no que se refere às atribuições dos profissionais de saúde bucal no PSF.

Outro ponto importante diz respeito ao acompanhamento e avaliação permanente das ações realizadas. Prevista pela Portaria no 267 do MS, essa prática também não parece ser comum no PSF do Distrito Sanitário Norte.

Além desses aspectos, é preciso destacar outros fatores limitantes ao trabalho desenvolvido pelos dentistas. Cabe citar estrutura física inadequada às atividades, disponibilidade de equipamento, instrumental e material adequados à realização de todas as ações previstas, ausência de um número maior de especialistas, falta de planejamento das atividades que leve em consideração as necessidades e expectativas da população, falta de capacitação dos profissionais para o trabalho em equipe.

Deve-se ressaltar como contraponto às dificuldades encontradas que os dentistas, em relação à autonomia e poder de decisão no trabalho, avaliam a sua condição de trabalho como boa ou razoável. Isso significa que os dentistas das UBSs do Distrito Sanitário Norte têm liberdade de atuar e decidir sob aspectos do seu trabalho, agilizando e facilitando o desenvolvimento de suas atividades. Esse fato é um aspecto positivo para a realização das ações de saúde bucal nas UBSs do PSF do Distrito Sanitário Norte.

Também merece destaque o fato de que a integração entre a ESB e a ESF é considerada boa pela maioria dos dentistas. A integração das ESBs com as ESFs pode ser vista como fator positivo na condução das atividades das UBSs no Distrito Sanitário Norte, por promover tanto a prática de ações coletivas quanto a prática de ações intersetoriais, e também, a abordagem multiprofissional, pontos importantes na filosofia de assistência à saúde trazida pelas diretrizes do PSF.

Para a maioria dos dentistas, a inclusão das ações de saúde bucal no PSF do Distrito Sanitário Norte foi muito positiva. Com isso, pode-se dizer que o PSF vem conseguindo imprimir um novo cenário no que diz respeito à saúde bucal da população do Distrito Sanitário Norte na medida em que tem conseguido ampliar o acesso da população por meio de um novo modelo de assistência à saúde. 
Concluindo, pode-se afirmar que o exame das condições de trabalho das ESBs no PSF revela que apesar das limitações encontradas pelos dentistas para a execução do seu trabalho vem sendo posto em prática um novo jeito de fazer saúde, que tem produzido mudanças nos índices relacionados à saúde bucal da comunidade.

\section{Referências bibliográficas}

ANDRADE, Luiz O. M.; BEZERRA, Roberto C. R.; BARRETO, Ivana Cristina de H. C. O Programa de Saúde da Família como estratégia de atenção básica à saúde dos municípios brasileiros. Revista de Administração Pública, v. 39, n. 2, p. 327-349, 2005.

BRASIL, Ministério da Saúde. Gestão Municipal de Saúde: textos básicos. Rio de Janeiro: Ministério da Saúde, 2001.

. Programa de Saúde da Família: ampliando a cobertura para consolidar a mudança do modelo de atenção básica. Brasília, 2003a. 2003b.

. Documento Final da Comissão de Avaliação da Atenção Básica. Brasília,

. Avaliação normativa do Programa Saúde da Família no Brasil: monitoramento da implantação e funcionamento das equipes de saúde da família - 2001/2002. Brasília: Ministério da Saúde, 2004.

. Ministério da Saúde. Secretaria Executiva. Programa Saúde da Família: equipes de saúde bucal. Brasília: Ministério da Saúde, 2002. Disponível em: <www. psfbrasil.com.br/biblio/informes/it34.pdf>. Acesso em: 7 dez. 2005.

. Ministério da Saúde. Portaria no 1.444, de 28 de dezembro de 2000.

. Ministério da Saúde. Portaria no 267/GM, de 6 de março de 2001.

NATAL. Secretaria Municipal de Saúde. Plano Municipal de Saúde: 2006-2009/Secretaria Municipal de Saúde de Natal, Natal, RN, 2006.

PREFEITURA MUNICIPAL DE NATAL. Secretaria Municipal de Saúde. (Re)desenhando a Rede de Saúde na Cidade do Natal, Secretaria Municipal de Saúde de Natal, Natal, RN, 2007.

. Lei no 3.878, de 7 de dezembro de 1989.

VIANA, A . L. D.; DAL POZ. M. R. A reforma do sistema de saúde no Brasil e o Programa Saúde da Família. Physis: Rev. Saúde Coletiva, v. 8, n. 2, p. 11-48, 1998. 